\title{
A qualidade da água de nascentes e cursos fluviais de baixa ordem como indicador de desafios de gestão de parques urbanos em Belo Horizonte/MG
}

\author{
The water quality of springs and low-order river channels as an indicator of urban park \\ management challenges in Belo Horizonte, Minas Gerais state, Brazil
}

Catharina de Oliveira Maia Graduanda em Geografia pela UFMG, Brasil catharinaolm@gmail.com

Gabriel Lucas Vieira Lázaro Graduando em Geografia pela UFMG, Brasil gabriel.lucas375@hotmail.com

Livia Oliveira Borges Dias Graduanda em Geografia pela UFMG, Brasil

liviaborgesd@gmail.com

Paulo Henrique Batista Graduando em Geografia pela UFMG, Brasil paulo.henrique.batista.96@gmail.com

Antônio Pereira Magalhães Jr. Professor Titular do Departamento de Geografia da UFMG, Brasil antonio.magalhaes.ufmg@gmail.com

Miguel Fernandes Felippe Professor do Departamento de Geociências da UFJF, Brasil

Fernando César da Costa Laboratório de Geomorfologia e Recursos Hídricos da UFMG, Brasil fernandocesar_mg@yahoo.com.br

\begin{abstract}
Resumo
Neste trabalho a qualidade da água de nascentes e de cursos fluviais de baixa ordem é investigada como indicadora de desafios de gestão de parques urbanos em Belo Horizonte (MG). Foram estudados o Parque Ecológico do Brejinho, o Parque Vila Clóris e o Parque Municipal Ursulina de Andrade Mello, todos na região norte da cidade. Os diferentes parâmetros analisados demonstram um quadro frequente de poluição, mesmo em cenários protegidos, principalmente pela remoção de poluentes superficiais por escoamento pluvial e disposição ocasional de lixo nas bacias de contribuição. Estas bacias abrangem significativas áreas externas aos parques, as quais são bastante urbanizadas. Por outro lado, os resultados também mostram o papel dos sistemas brejosos associados às nascentes difusas no enriquecimento geoquímico das águas superficiais, indicando a relevância da proteção das áreas úmidas (wetlands) urbanas. O trabalho reforça que os processos de gestão dos parques urbanos devem contemplar a integridade dos sistemas hídricos e a dinâmica de uso e ocupação do solo nas bacias de contribuição, dentro e fora das unidades de conservação.
\end{abstract}

Palavras-chave: Sistemas hídricos urbanos, Nascentes difusas, Gestão ambiental. 


\begin{abstract}
In this paper, the water quality of springs and low-order fluvial systems is investigated as an indicator of the management challenges of urban parks in Belo Horizonte (Minas Gerais state, Brazil). The Parque Ecológico do Brejinho, Parque Vila Clóris and Parque Municipal Ursulina de Andrade Mello municipal parks were studied in the northern region of the city. The different geochemical parameters show a frequent picture of pollution, even in scenarios of conservation units, mainly due to the removal of surface pollutants by rainwater and occasional disposal of waste in the upstream pluvial basins. These basins cover significant areas outside the parks, which are quite urbanized. On the other hand, the results also show the role of swampy systems associated with diffuse springs in the geochemical enrichment of surface waters, indicating the relevance of urban wetlands' protection. The results reinforce that the urban parks management processes must contemplate the integrity of the water systems and the land use and occupation dynamics in the contribution basins, inside and outside the conservation units.
\end{abstract}

Keywords: Urban water systems, Diffuse springs, Environmental management.

\title{
1. INTRODUÇÃO
}

No Brasil, os parques são considerados como áreas destinadas à proteção de ecossistemas naturais de significativa relevância ecológica e beleza paisagística, possibilitando a elaboração de pesquisas científicas, atividades de educação e interpretação ambiental, lazer em contato com a natureza e turismo ecológico $(\mathrm{PBH}, 2020)$. Neste sentido, os parques são áreas propícias para viabilizar a proteção de elementos do ambiente físico, tais como a cobertura vegetal e os recursos hídricos, e proporcionar, ao mesmo tempo, opções de pesquisas e lazer. Entretanto, no meio urbano os parques se configuram em áreas fragmentadas espacialmente e sofrem importantes pressões humanas no seu entorno. A proteção da integridade ambiental dos parques urbanos se configura, portanto, em um desafio constante para os aparatos institucionais municipais e respectivas políticas públicas. A conciliação entre os objetivos de proteção ambiental e de usos e ocupação do solo no meio urbano exige, geralmente, um diálogo entre diferentes políticas e estratégias de gestão territorial.

As condições ambientais de parques urbanos podem sinalizar os seus desafios de gestão. Martins et al., (2019) elaboraram uma proposta baseada em sistemas métricos para avaliar indicadores de conservação e de uso público no Parque Nascentes do Belém em Curitiba (PR), a fim de verificar o atendimento às funções esperadas. Bovo et al., (2011) estudaram a infraestrutura e a qualidade paisagística de parques urbanos de Maringá (PR) por meio de protocolos de avaliação rápida de cunho ambiental. Em Belo Horizonte (MG), Felippe e Magalhães Jr. (2012) analisaram a qualidade ambiental de três parques urbanos com base na qualidade das águas de nascentes e em um protocolo de avaliação de impactos macroscópicos. Ainda na capital mineira, Ferreira (2019a), Ferreira e Magalhães Jr (2018) e Ferreira et al., (2019b) estudaram o estado ambiental, as pressões e impactos antrópicos em parques urbanos por meio da investigação de áreas úmidas (wetlands). 
As nascentes são particularmente sensíveis aos processos de poluição, já que refletem os mecanismos de exfiltração das águas subterrâneas, cuja qualidade tende a ser melhor do que a das águas superficiais em áreas antropizadas. Em contato com o ambiente externo, a água pode sofrer diferentes reações geoquímicas comandadas pelo clima, pela cobertura vegetal, pela composição dos materiais do substrato e pelas atividades humanas (FELIPPE et al., 2013; MAGALHÃES Jr et al., 2018). Desse modo, diversos parâmetros geoquímicos podem sinalizar estas transformações, como os Sólidos Totais Dissolvidos (STD), que podem refletir influências antrópicas nas concentrações de certos íons (ZHU et al., 2012), ou os sulfatos na água de abastecimento público, já que altas concentrações podem levar a complicações intestinais, como a diarreia (RAMOS et al., 2007). De uma forma geral, os produtos geoquímicos dos processos de meteorização sub-superficial e superficial de rochas e formações superficiais, bem como dos processos de poluição, podem ser eficientemente detectados por meio da análise qualitativa das águas. Desta forma, a água das nascentes de cursos d'água pode espelhar a assinatura geoquímica (composição) dos aquíferos de origem (SALGADO et al., 2004; FELIPPE et al., 2015; FELIPPE; MAGALHÃES Jr, 2016).

Neste cenário, o trabalho buscou apontar desafios de gestão dos parques municipais de Belo Horizonte a partir da qualidade da água de nascentes e canais fluviais de baixa ordem. O trabalho pode complementar os resultados de outros estudos sobre a qualidade da água em parques municipais da cidade e contribuir para a sua proteção (FELIPPE et. al., 2012; ALMEIDA et al., 2018; FERREIRA; MAGALHÃES Jr, 2018; FERREIRA, 2019a; FERREIRA et al., 2019b).

\section{PROCEDIMENTOS METODOLÓGICOS}

A pesquisa partiu de pesquisa bibliográfica e cartográfica, com destaque para a plataforma "Infraestrutura de Dados Espaciais de Belo Horizonte, IDE BH-GEO”. Foram também analisadas imagens de satélite disponibilizadas no Google Earth Pro, com o intuito de verificar a contextualização espacial dos parques municipais da cidade.

A seleção dos parques e locais de estudo foi determinada pela possibilidade de acesso a nascentes e respectivos cursos d'água de $1^{\text {a }}$ ordem segundo Strahler (1952). Também foram considerados parques no mesmo contexto geológico e climático que possibilitasse a comparação do background fisiográfico, mas com diferenças nos níveis de intervenção antrópica no seu interior e entorno. Finalmente, buscou-se priorizar o critério da logística da amostragem, considerando que estudos de caso relativamente próximos poderiam permitir campanhas de campo mais práticas e eficientes para se coletar amostras de água e transportá-las ao Laboratório de Geomorfologia e Recursos Hídricos do Instituto de Geociências (IGC) da Universidade Federal de Minas Gerais (UFMG). Nesse cenário, foram selecionados, na região da Pampulha, o Parque Ecológico do 
Brejinho (bairro São Francisco) e o Parque Municipal Ursulina de Andrade Mello (bairro Castelo), bem como o Parque Municipal Vila Clóris (bairro Vila Clóris), na região Norte na cidade (Fig. 1). Esses parques estão inseridos na bacia do Ribeirão do Onça, que atualmente se localiza na Classe de Enquadramento 3 em termos de qualidade da água (CBH RIO DAS VELHAS, 2020).

Os pontos monitorados foram registrados em aparelho GPS Garmin, modelo MAP 60CSx, $n^{\circ}$ 010-N0422-00, e os mapas elaborados no software Quantum GIS versão 3.10. Os pontos foram codificados de modo a facilitar a sua identificação: as nascentes foram codificadas com o final 0 e os cursos d'água de $1^{\mathrm{a}}$ ordem com o final 1. Desse modo, foram estabelecidos os pontos de monitoramento expressos na Figura 2. Os critérios de seleção dos pontos de amostragem variaram de acordo com os diferentes contextos dos parques. No Parque Ursulina de Mello, as nascentes e os cursos d'água escolhidos encontravam-se em áreas de fácil acesso, bem próximas aos espaços de lazer. No Parque Vila Clóris foram selecionadas as únicas nascentes encontradas e seus cursos d'água associados. Já no Parque Ecológico do Brejinho buscou-se uma área que não estivesse impactada pelas obras de implantação da bacia de contenção do córrego São Francisco, sendo selecionada a única nascente difusa local, a qual forma um pequeno brejo que dá nome ao parque.

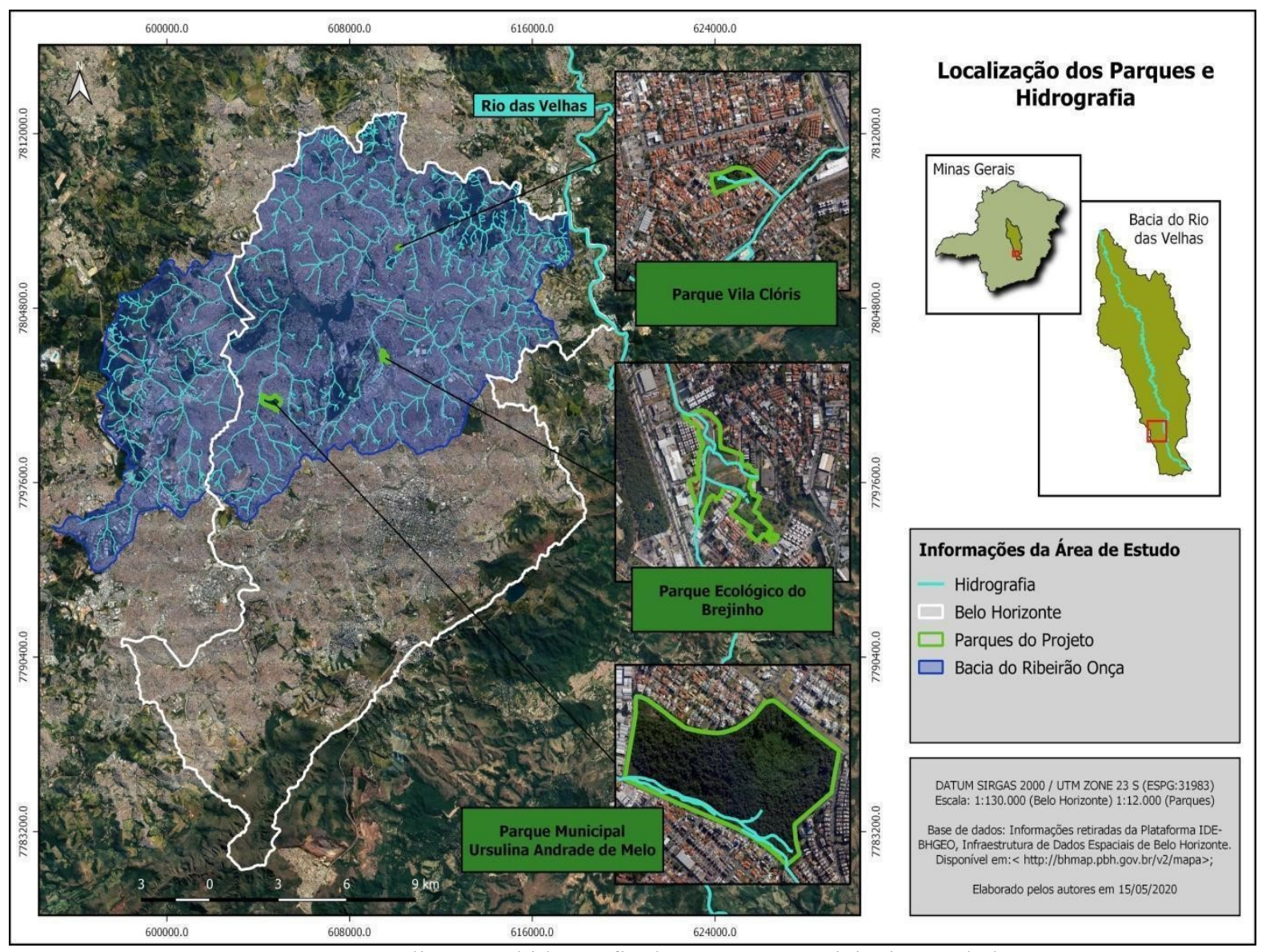

Figura 1 - Localização e hidrografia dos parques municipais estudados.

Fonte: Elaborado pelos autores. 

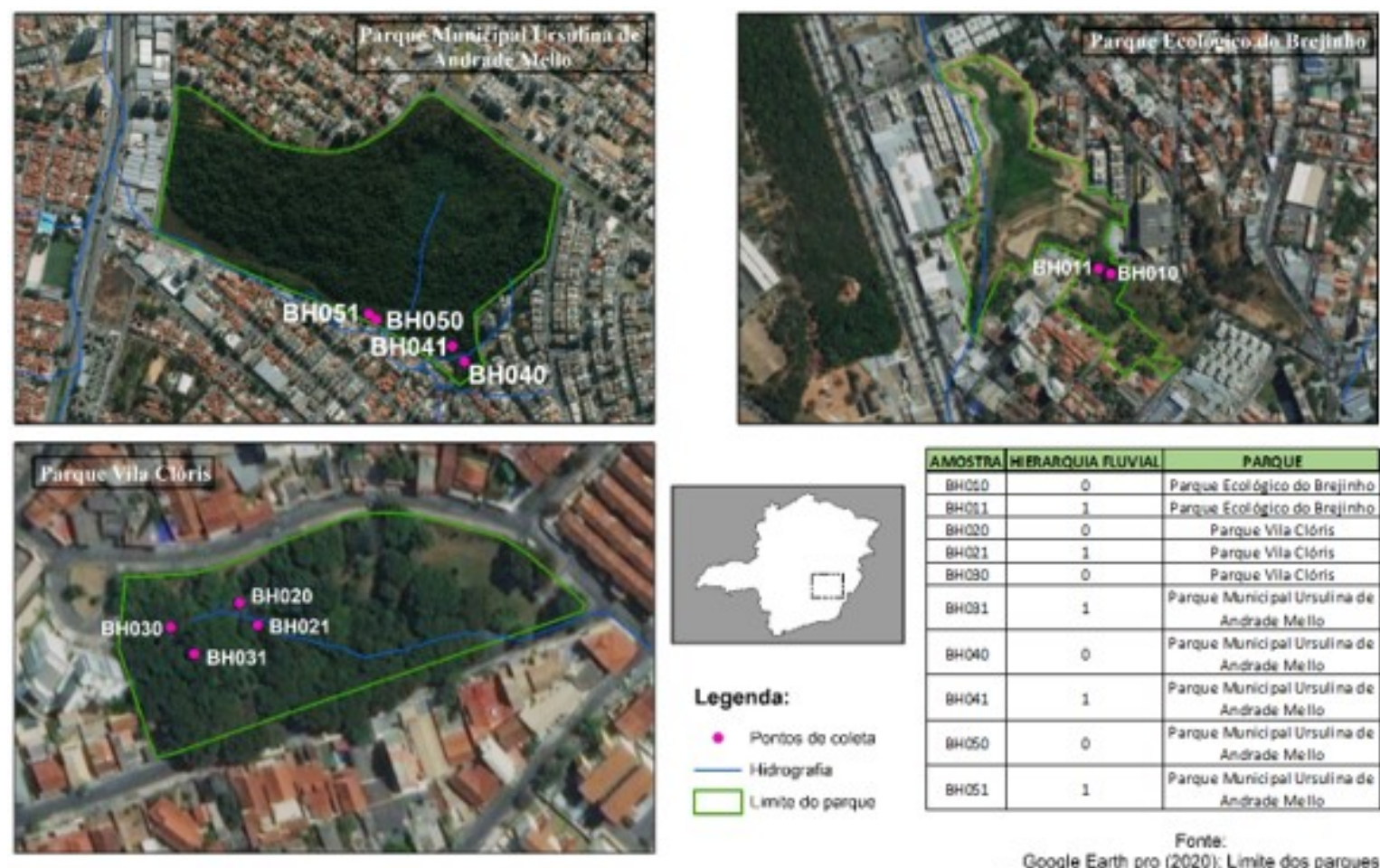

Qoogle Earth pro (2020) Limite dos parques ICAM (2020) Hidrografa

Elaborads pelos autores

Figura 2 - Parques urbanos e pontos de monitoramento selecionados. Código 0: nascentes; Código 1: canais de $1^{\mathrm{a}}$ ordem.

Após a seleção dos parques e a definição dos pontos de monitoramento, foram realizadas quatro campanhas de campo compreendendo as estações úmida e seca, dada a sazonalidade típica do clima tropical no qual Belo Horizonte se insere. Três ocorreram nos meses de junho, setembro e dezembro de 2018, respectivamente, e a última em março de 2019. Em cada campanha foi elaborado um relatório com a descrição das condições de proteção dos parques e dos pontos monitorados. Buscou-se registrar nos relatórios se nos pontos de amostragem e nos parques havia circulação de pessoas e animais domésticos, presença de lixo, ocorrência de mau cheiro e se houve intervenção na vegetação, nas nascentes ou nos cursos d'água.

A seleção dos parâmetros foi baseada em Ferreira et al., (2017), Magalhães Jr et al., (2018), Felippe et al., (2019) e Rocha et al., (2019), que abordam a qualidade da água de nascentes e cursos d'água de ordem inferior em meio tropical. Os parâmetros deveriam sinalizar o background geológico e também influências antrópicas em termos de poluição; sendo, para esse fim, selecionados os parâmetros: Sólidos Totais Dissolvidos (STD), pH, Condutividade Elétrica (CE), Alcalinidade, Cálcio, Magnésio, Potássio, Sódio, Sulfatos e Demanda Bioquímica de Oxigênio (DBO).

As amostras foram coletadas com uma seringa e armazenadas em frascos âmbar de polipropileno com capacidade de $500 \mathrm{ml}$. Para cada ponto de monitoramento foram coletados dois 
frascos (1L) para viabilizar todas as análises. Os frascos de plástico foram lavados previamente com água ultra purificada para evitar quaisquer contaminações. Após cada campanha de coleta as amostras foram analisadas no Laboratório de Geomorfologia e Recursos Hídricos do Instituto de Geociências da UFMG, onde foram utilizados: balança analítica modelo Marte AY220 para pesagem anterior e posterior à secagem das cápsulas de porcelana $(500 \mathrm{ml}$ de amostras pipetadas e secadas), visando a análise de Sólidos Totais Dissolvidos (STD); Phmetro modelo Tecnopom mPa210 para medição do $\mathrm{pH}$; Condutivímetro modelo Tecnopom $m C a-150$ para determinação da condutividade elétrica. As análises químicas foram realizadas em consonância com as normas do Standard Methods for Examination of Water and Wastewater (APHA et al., 2012).

\section{CONTEXTUALIZAÇÃO MUNICIPAL: A CIDADE DE BELO HORIZONTE}

A cidade foi planejada por meio de um projeto urbanístico caracterizado por linearidade, salubridade, geometrização, comodidade e hierarquização dos espaços (HOYUELA JAYO et al., 2015), desconsiderando a topografia e a rede hidrográfica. A cidade foi configurada sob influência de políticas higienistas baseadas na retificação de canais fluviais, já que o aumento das vazões em períodos de chuva traria fluxos poluídos causadores de patologias (BRITO, 1943). Desse modo, o planejamento foi marcado por canalizações e tamponamentos de cursos d'água para a expansão de vias urbanas, suprimindo os sistemas hídricos da paisagem e gerando uma cidade desprovida de cursos d'água superficiais (TOCHETTO; FERRAZ, 2015; ALMEIDA; SANTOS, 2019).

Inicialmente planejada para comportar cerca de 200 mil habitantes (FJP, 1997), o boom demográfico a partir dos anos 1950/60 e a industrialização fizeram a malha urbana se expandir para outros vetores (Norte/Pampulha e Oeste/Bairro Industrial). Consequentemente, a maior parte da cobertura vegetal foi retirada e, com a maior impermeabilização do solo, os períodos de alta pluviosidade passaram a gerar recorrentes cenários de inundação (CRUZ, 2020). Atualmente, Belo Horizonte é o centro político-administrativo e financeiro do estado, com uma população estimada em 2,5 milhões de habitantes e densidade demográfica de cerca de 7.000 hab./km² (IBGE, 2010).

Em termos fisiográficos, a cidade se insere na Depressão de Belo Horizonte, uma unidade geológico-geomorfológica a sul da Serra do Espinhaço. A cidade tem como substrato as rochas do Supergrupo Minas, nas porções sul-sudeste, e do embasamento cristalino arqueano do Complexo Belo Horizonte que domina a região norte do município (CPRM, 2000). As primeiras, principalmente quartzitos, itabiritos e filitos, coincidem com a porção norte do domínio do Quadrilátero Ferrífero, onde sustentam a Serra do Curral, símbolo e referência espacial da capital. O relevo reflete, portanto, a diferenciação geológica, e o conjunto serrano da porção meridional do município passa gradualmente a suavizado em direção à porção norte, onde predominam colinas 
com vertentes convexas e de topos planos e arqueados, cuja dissecação fluvial configura vales mais amplos de fundo chato (SILVA et al., 1995; SANTOS, 2001). O modelado está associado, também, a uma variedade de solos, particularmente Latossolos Vermelho-Amarelos e Vermelhos e Argissolos Vermelho-Amarelos e Vermelhos na Depressão de Belo Horizonte, e Cambissolos Háplicos no sistema da Serra do Curral (IBGE, 2001). A cidade está situada nas sub-bacias dos ribeirões Arrudas, que drena a porção sul da cidade, e do Onça, na porção norte, ambos afluentes da margem esquerda do Rio das Velhas, um dos maiores afluentes do rio São Francisco. A região marca uma zona de transição entre os biomas Cerrado e Mata Atlântica, ambos bastante suprimidos ou descaracterizados na Região Metropolitana de Belo Horizonte - RMBH (IBGE, 2004).

Finalizando o panorama fisiográfico, o clima apresenta características do tipo subquente semiúmido com 4 a 5 meses de seca (IBGE, 2002). A sazonalidade é bem definida (Fig. 3 e 4), com chuvas concentradas entre outubro e março (INMET, 2017).

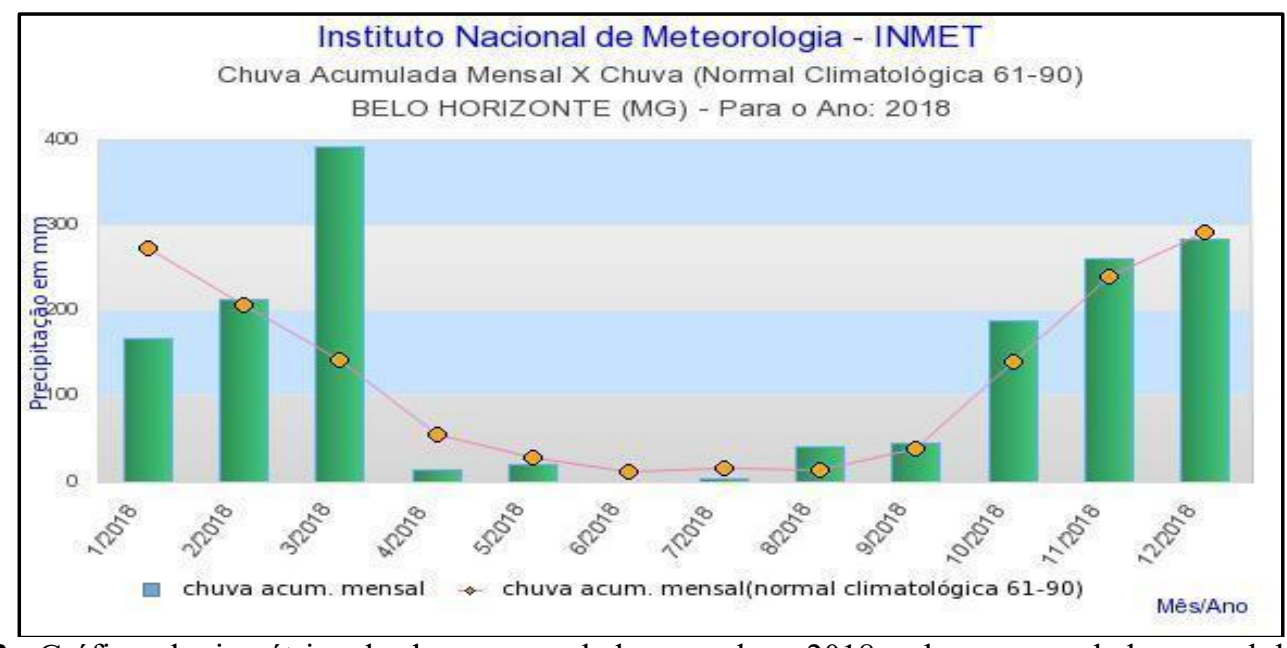

Figura 3 - Gráfico pluviométrico da chuva acumulada mensal em 2018 e chuva acumulada mensal da Normal Climatológica 1961-1990, com destaque para o período de monitoramento (junho a dezembro de 2018).

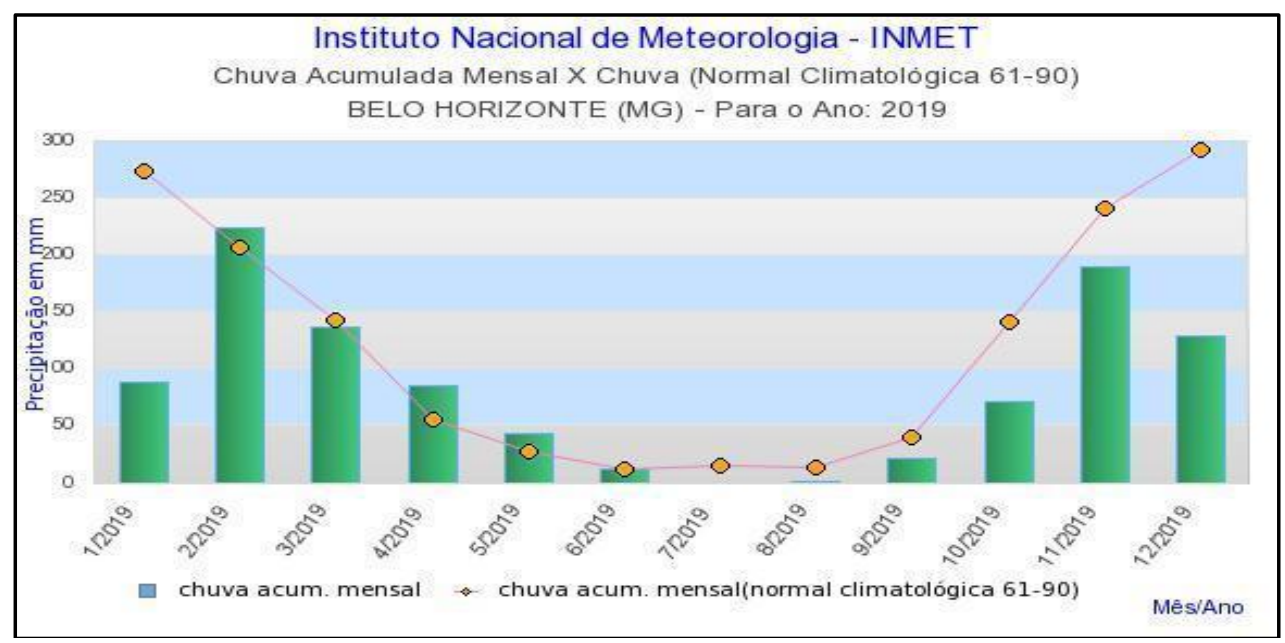

Figura 4 - Gráfico pluviométrico da chuva acumulada mensal em 2019 e chuva acumulada mensal da Normal Climatológica 1961-1990, com destaque para o período de monitoramento (janeiro a março de 2019) 


\section{PARQUES MUNICIPAIS ESTUDADOS}

Os parques urbanos de Belo Horizonte são geridos pela Fundação de Parques Municipais e Zoobotânica (FPMZB), vinculada à Secretaria de Meio Ambiente Municipal. A Fundação foi criada pela lei $\mathrm{n}^{\mathrm{o}} 11.065$, de $1^{\circ}$ de agosto de 2017, a partir da fusão entre a Fundação Zoobotânica e a Fundação de Parques Municipais (FPM). Os parques municipais se configuram como fragmentos protegidos frente à urbanização acelerada na $\mathrm{RMBH}$, viabilizando a proteção de recursos naturais e proporcionando conforto e lazer aos cidadãos; tendo, desse modo, a Prefeitura da capital o controle administrativo em mais de 70 parques municipais, a maioria se concentrando na região centro-sul da cidade (PBH, 2020).

Os parques estudados situam-se em bairros residenciais da região norte da cidade, próximos a importantes avenidas. No contexto de artificialização generalizado das bacias hidrográficas, os parques ainda compreendem fragmentos com maior integridade ecológica relativa. Não foram observadas alterações antrópicas significativas na cobertura vegetal das áreas estudadas durante a pesquisa, apesar das variações naturais derivadas da sazonalidade (Fig. 5 a 7) e da presença resíduos sólidos durante as campanhas de coleta de dados. Para a compreensão prévia das bacias de contribuição dos pontos de coleta da água, utilizou-se o base map do IDE-Sisema com a ativação das camadas 'Curvas de Nível $(30 \mathrm{~m})$ ' e 'Drenagem da Bacia Hidrográfica do Rio São Francisco'. Nota-se, portanto, que significativa extensão das áreas de contribuição situam-se fora dos parques estudados, em zonas densamente ocupadas por residências ou equipamentos urbanos (Fig. 8).
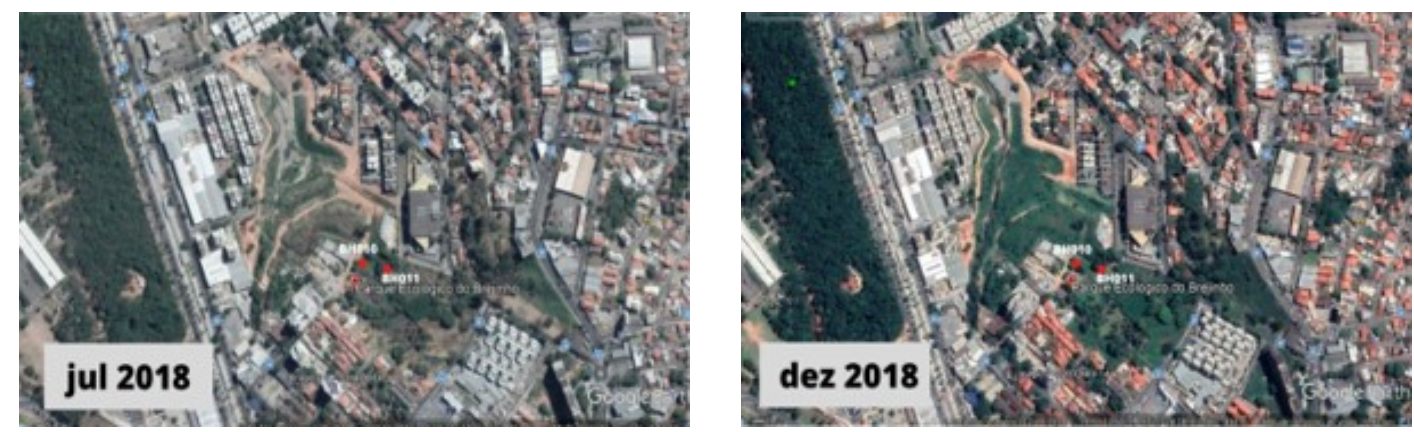

Pontos monitorados no Parque Ecológico do Brejinho

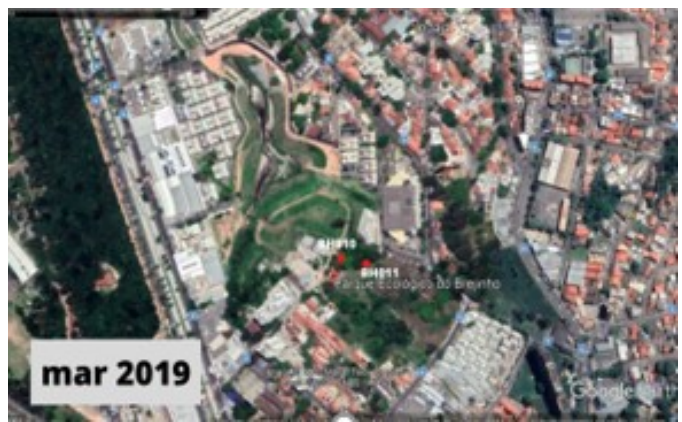

Figura 5 - Parque Ecológico do Brejinho. 

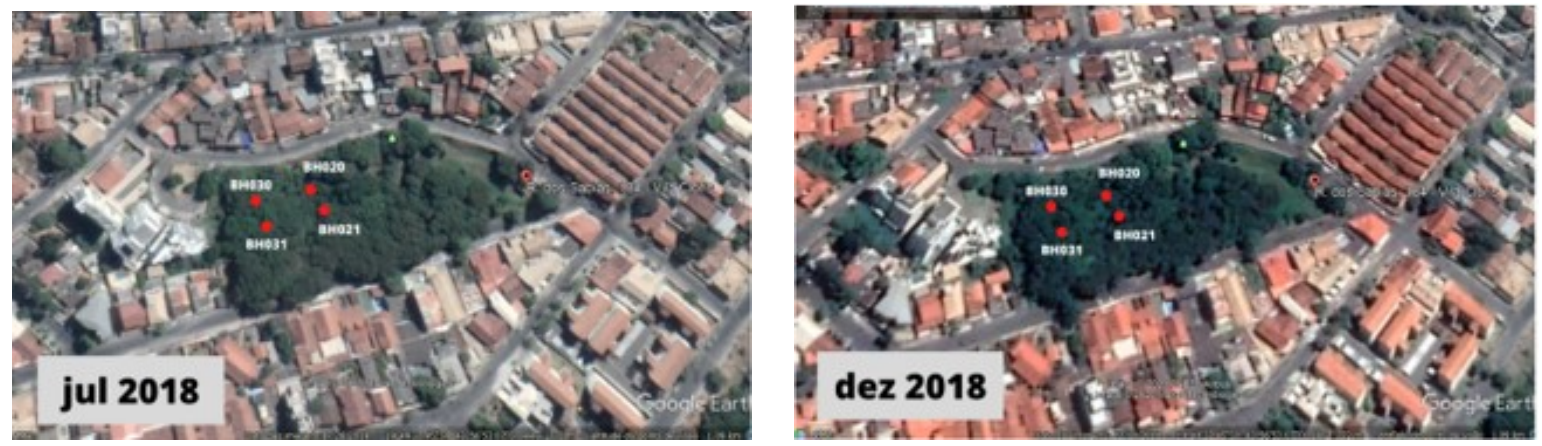

Pontos monitorados no Parque Vila Clóris

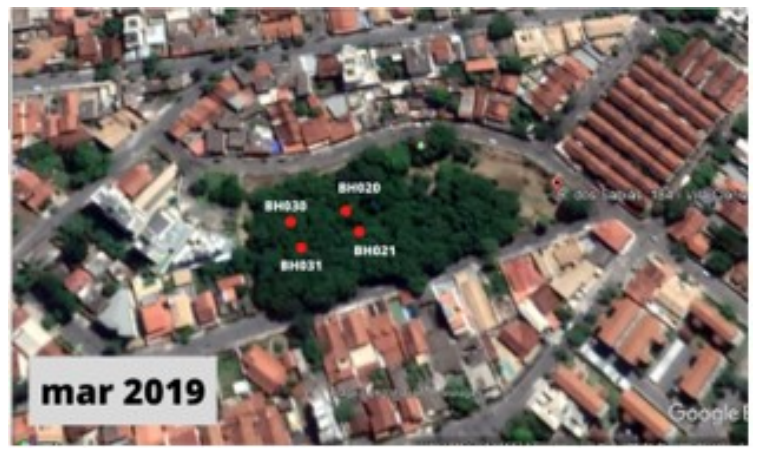

Figura 6 - Parque Vila Clóris.
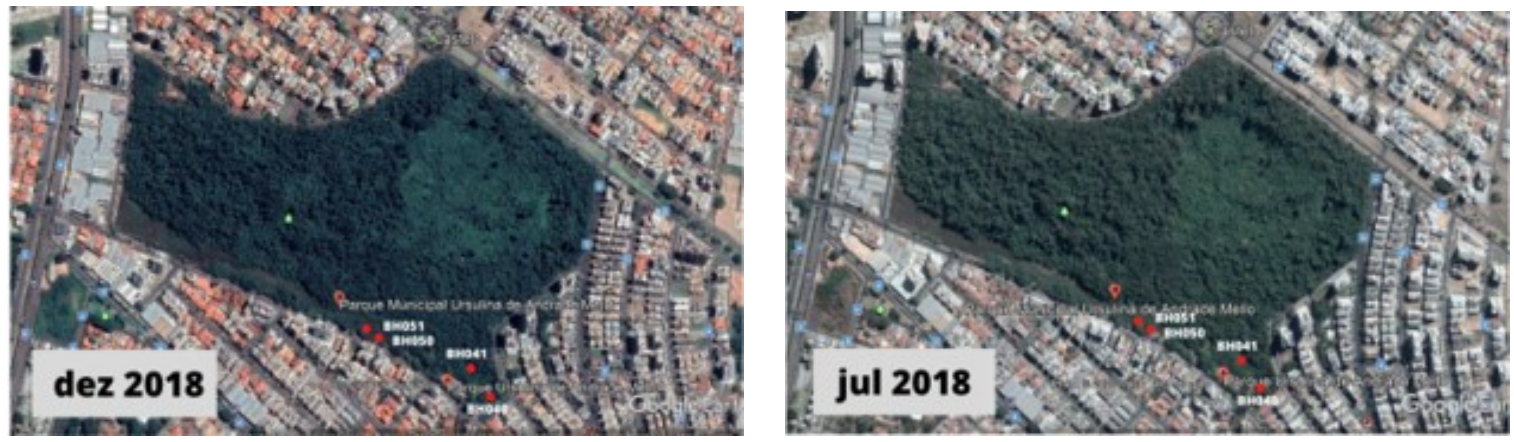

Pontos monitorados no Parque Municipal Ursulina de Andrade Melo

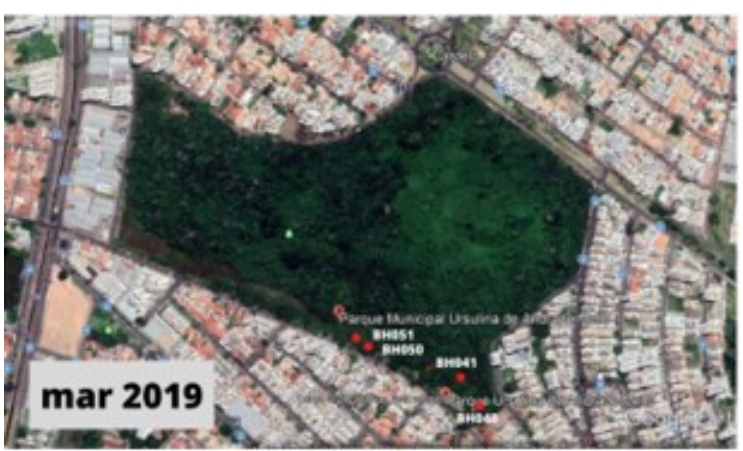

Figura 7 - Parque Municipal Ursulina de Andrade Melo. 


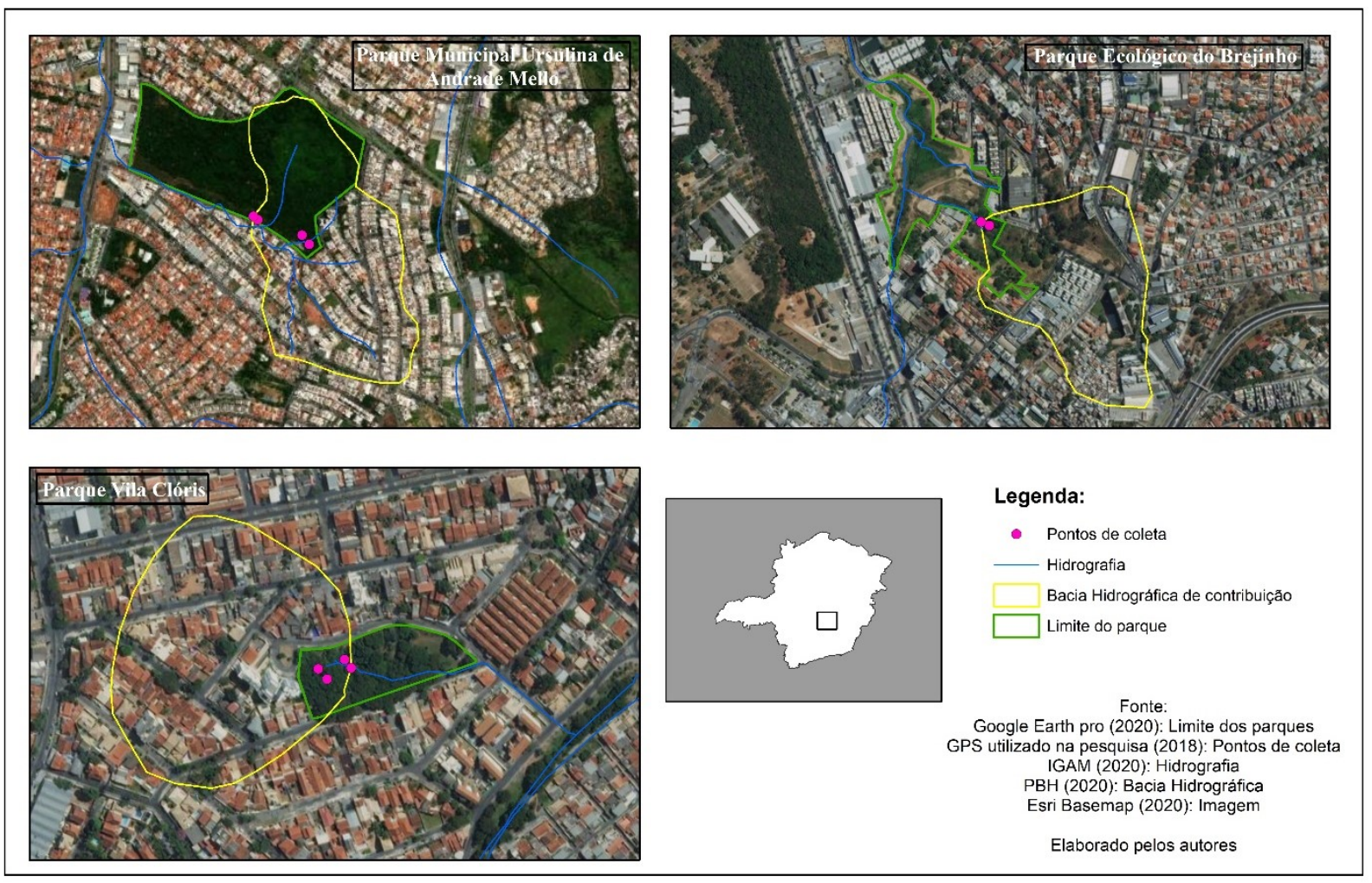

Figura 8 - Bacias hidrográficas de contribuição dos parques estudados.

Localizado no bairro São Francisco, o Parque Ecológico do Brejinho foi criado em 2007, ocupando uma área aproximada de $57.600 \mathrm{~m}^{2}(\mathrm{PBH}, 2020)$. O Parque é drenado pela bacia do córrego São Francisco, afluente do córrego Engenho Nogueira, um dos tributários do Ribeirão do Onça.

O histórico do Parque, descrito por Ferreira et al., (2019b), tem relação direta com as recorrentes inundações na bacia do córrego Engenho Nogueira, derivadas dos problemas de macrodrenagem na região. A Prefeitura aprovou, em 2012, a implantação de uma bacia de detenção abrangendo a Área de Preservação Permanente (APP) da microbacia do Córrego São Francisco/Assis das Chagas. A concepção da estrutura buscou aumentar a capacidade de retenção hídrica e frear as inundações nos períodos chuvosos, os quais impactaram o Aeroporto da Pampulha. As obras, iniciadas em 2014, levaram à supressão de grande parte da cobertura vegetal local, assim como do extenso brejo que preenchia a área central do Parque. Apesar dos importantes impactos das obras, os pontos monitorados não foram afetados, já que se situam a montante das mesmas, em área de mata secundária em fundo de vale. Foi possível mensurar a vazão nos cursos d'água e na nascente: médias de 0,048 mL/s (BH010) e 0,212 mL/s (BH011) na estação seca, e médias de $0,039 \mathrm{~mL} / \mathrm{s}(\mathrm{BH} 010)$ e $0,217 \mathrm{~mL} / \mathrm{s}$ (BH011) na estação úmida. Paradoxalmente, o ponto BH010 apresentou queda de 19\% na média da estação úmida, enquanto o ponto BH011 apresentou um aumento de $2 \%$. Na segunda campanha de campo durante a estação seca, houve o registro em 
campo de que as coletas de água foram realizadas em um momento pós-chuva, o que deve ter contribuído para a queda do valor na média da estação úmida para o ponto da BH010.

À montante da bacia de contribuição dos pontos amostrais do Parque há um condomínio residencial, uma unidade hospitalar, uma transportadora e vias públicas com tráfego significtivo. A nascente BH010 é de tipo difusa e forma ambiente brejoso, apresentando vegetação herbácea que está degradada e poluída por lixo doméstico. Já o ponto BH011 apresenta vegetação herbácea e de porte arbustivo-lenhoso, pouco degradada (Fig. 9).

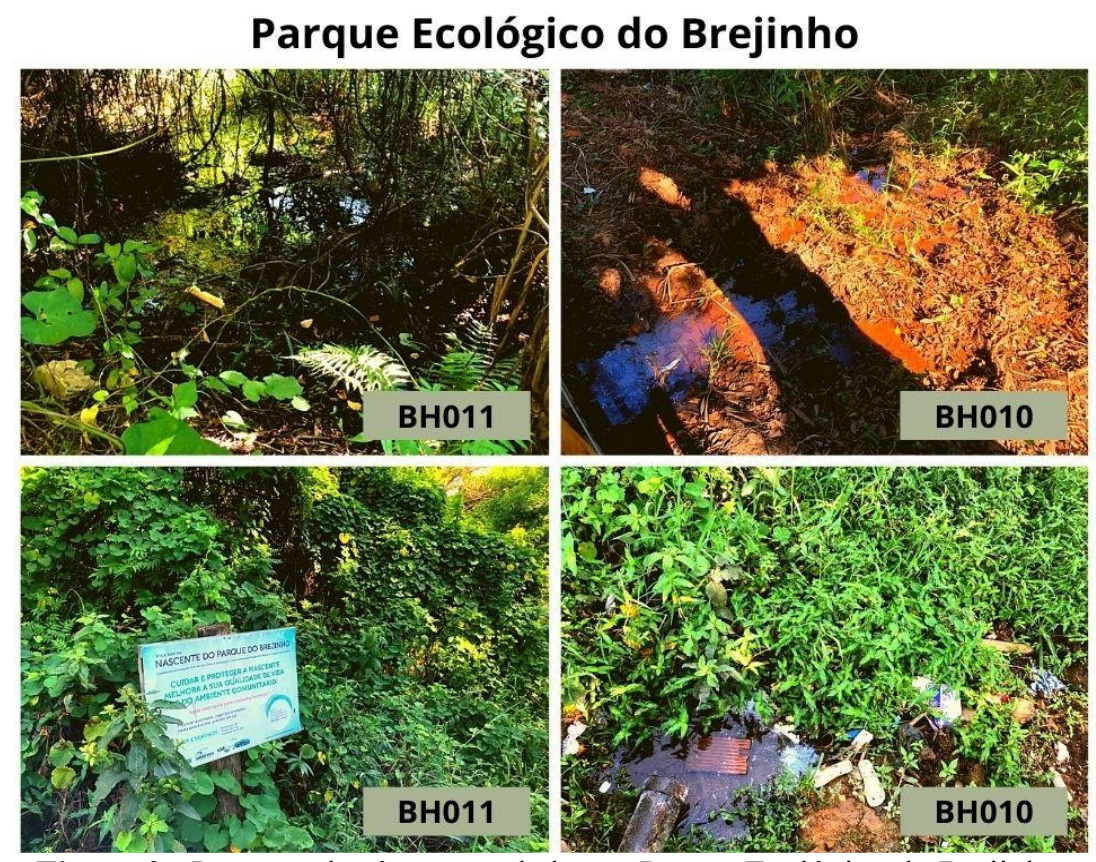

Figura 9 - Imagens das áreas estudadas no Parque Ecológico do Brejinho.

O Parque Vila Clóris possui cerca de $9.000 \mathrm{~m}^{2}$ e se situa na bacia do córrego do Embira, afluente do ribeirão Isidoro (PBH, 2018). Apesar de implantado em 2008 com o objetivo de proteger as nascentes do córrego Bacuraus, o Parque ainda não está aberto ao público, encontrandose em condição análoga ao abandono. Por não haver sistema de vigilância, ocorrem esporádicas invasões de moradores locais e durante as campanhas foram encontrados pequenos acumulados de lixo doméstico, como garrafas e sacos plásticos, dentro das dependências do parque. As nascentes BH020 e BH030 são do tipo difusas e formam sistemas brejosos. O sistema BH020-021 se encontra em área com vegetação arbórea onde se destaca um extenso bananal (Fig. 10). Já o sistema BH030031 está em área plana com vegetação herbácea, formando um ambiente brejoso e redutor. A vazão pôde ser mensurada somente no sistema BH020-021, na estação seca: médias de 0,028 mL/s (BH020) e 0,035 mL/s (BH021). Na estação úmida houve aumento considerável da vazão e presença de resíduos sólidos na área. O sistema BH030-031, por sua vez, se configura como uma área úmida brejosa, dificultando as medições. 
A bacia de contribuição das nascentes extrapola os limites do Parque e está majoritariamente inserida na malha urbana, em um bairro predominantemente residencial.

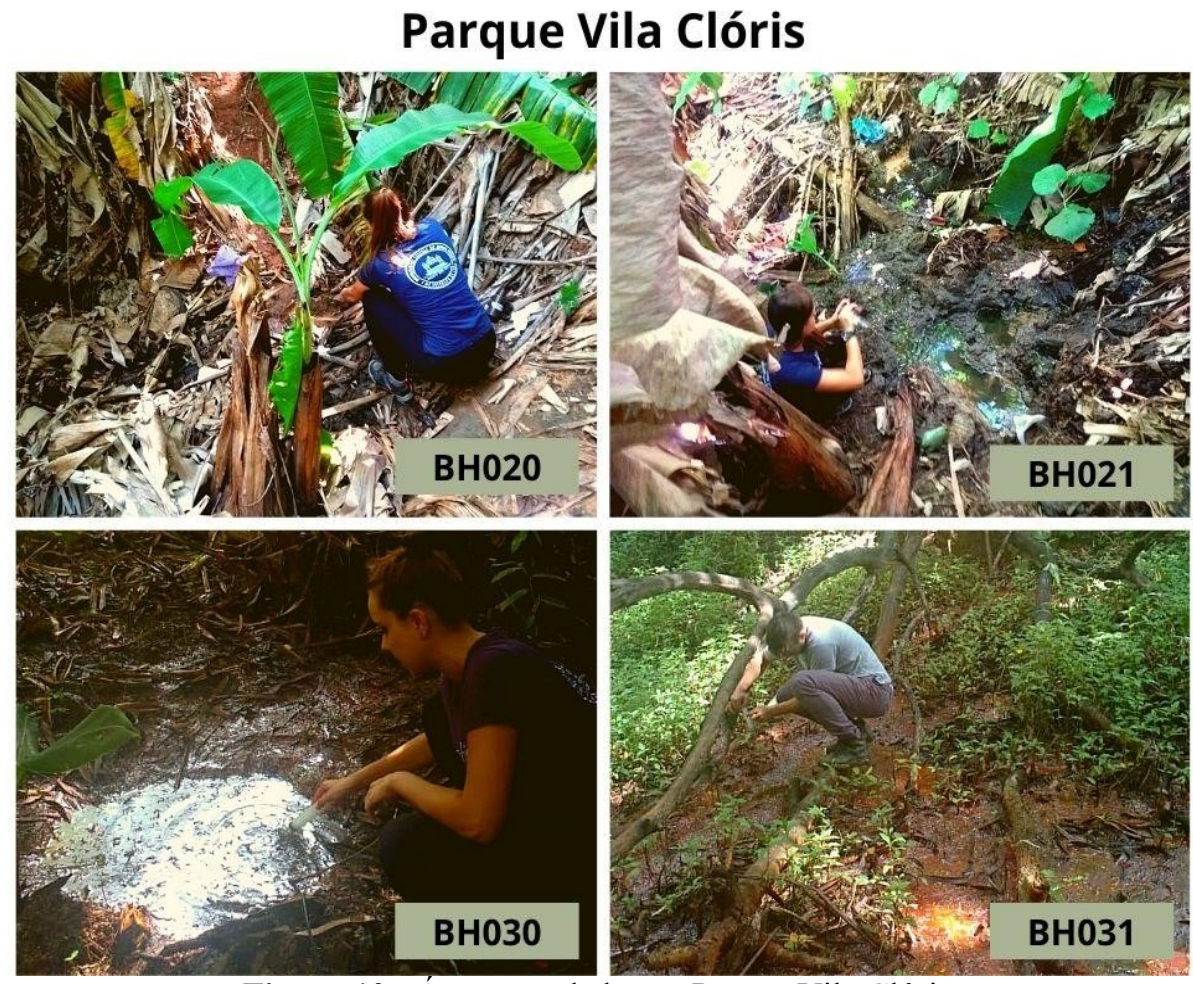

Figura 10 - Áreas estudadas no Parque Vila Clóris.

O Parque Ursulina de Andrade Mello, situado no bairro Castelo, possui cerca de 312.000 $\mathrm{m}^{2}$ de área e apresenta a cobertura vegetal mais densa dentre os Parques estudados, com $80 \%$ de mata nativa (PBH, 2019). A área se insere na bacia do córrego São Francisco, contribuinte do Ribeirão da Onça que é afluente do Rio das Velhas.

O Parque é um espaço com boa manutenção e diversas opções de lazer como pista de caminhada e equipamentos de ginástica, brinquedos, mesas e bancos, sendo bastante utilizado para a prática de atividades físicas. O entorno é delimitado por avenidas e ocupado por moradias e comércios. Os pontos monitorados envolvem nascentes difusas (BH040 e BH050) situadas em área plana brejosa com vegetação densa. As nascentes são bem protegidas e de fácil acesso (Fig. 11). Os cursos d'água (BH041 e BH051) apresentam contexto ambiental semelhante ao das respectivas nascentes, sendo margeados pela cerca limítrofe do parque e próximos (cerca de $4 \mathrm{~m}$ ) à área residencial do entorno. Não foi possível mensurar a vazão das nascentes BH050 e BH040, já que são do tipo difusa. Os cursos d'água apresentaram vazões médias de 0,422 mL/s (BH041) e 0,078 mL/s (BH051) na estação seca, e de 0,245 mL/s (BH041) e 0,286 mL/s (BH051) na estação úmida. Paradoxalmente, o ponto BH041 apresentou queda de 58\% na média da estação úmida, enquanto o ponto BH051 apresentou um aumento de 267\%. Em dezembro de 2018 o local do ponto BH051 
estava isolado por uma faixa da prefeitura visando proteger a área. Além disso, notou-se expressivo aumento do porte vegetacional nos pontos BH041 e BH051, em relação ao período seco.

As bacias de contribuição dos pontos analisados apresentam significativa extensão fora dos parques, em área predominantemente residencial.

\section{Parque Ursulina de Andrade Mello}
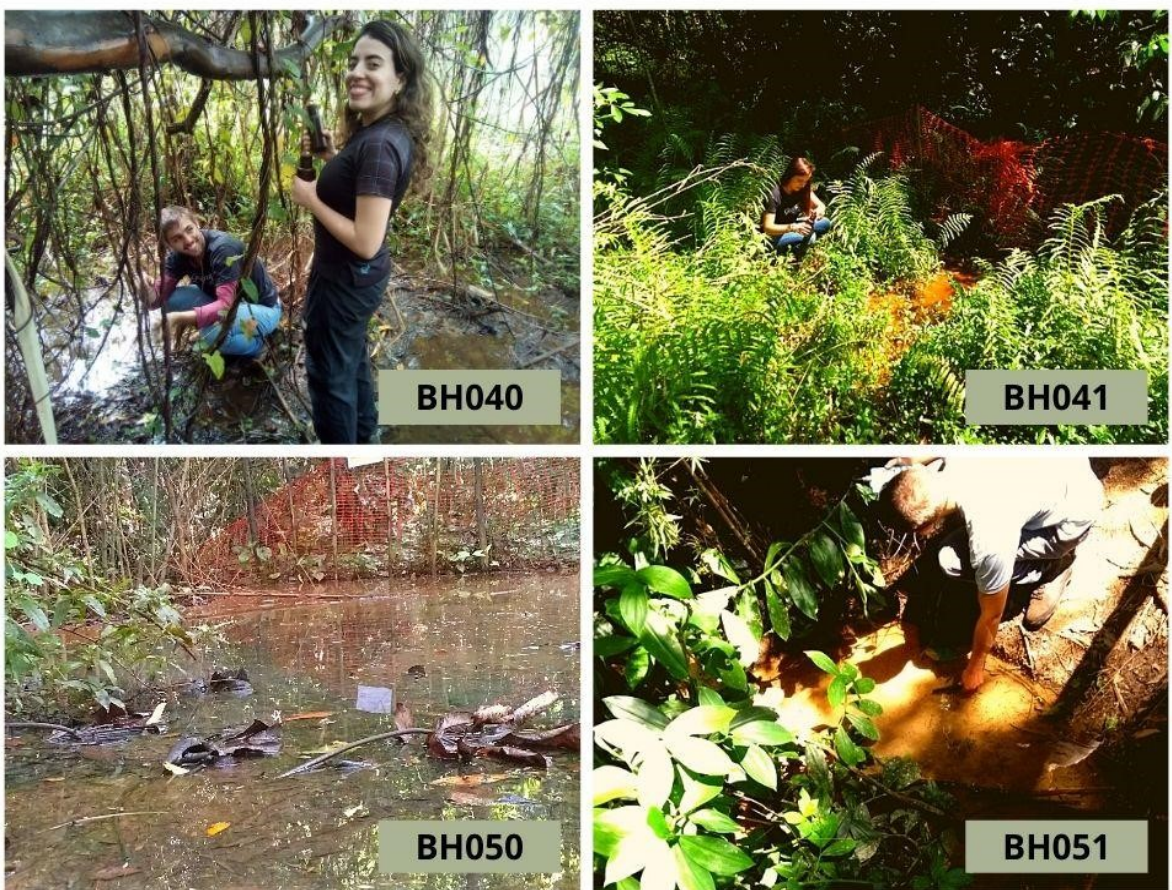

Figura 11 - Áreas estudadas no Parque Municipal Ursulina de Andrade Mello.

\section{O QUADRO GEOQUÍMICO DAS ÁGUAS SUPERFICIAIS}

Os resultados das análises geoquímicas estão expressos nas tabelas 1 a 10 e embasam a discussão, realizada a seguir, da realidade dos parques quanto ao estado das águas superficiais.

Tabela 1: Resultados de $\mathrm{pH}$.

\begin{tabular}{|c|c|c|c|c|c|c|c|c|c|c|c|c|c|c|c|}
\hline \multirow[b]{2}{*}{ Parque } & \multirow[b]{2}{*}{ AMOSTRA } & \multicolumn{4}{|c|}{$\mathrm{pH}$} & \multicolumn{3}{|c|}{ Variação entre campanhas (\%) } & \multicolumn{4}{|c|}{$\begin{array}{l}\text { Variação entre nascentes e } \\
\text { cursos d’água (\%) }\end{array}$} & \multicolumn{2}{|c|}{ Média aritmética } & \multirow{2}{*}{$\begin{array}{c}\text { Desvio padrão } \\
\text { Amostra }\end{array}$} \\
\hline & & jun/18 & set/18 & dez/18 & $\operatorname{mar} / 19$ & jun/set & set/dez & dez/mar & jun/18 & set/18 & $\operatorname{dez} / 18$ & mar/19 & $\begin{array}{c}\text { Estação } \\
\text { seca } \\
\text { (jun/set) }\end{array}$ & $\begin{array}{c}\text { Estação } \\
\text { úmida } \\
\text { (dez/mar) }\end{array}$ & \\
\hline \multirow{2}{*}{ PEB } & $\mathrm{BH} 010$ & 7.10 & 7.35 & 7.56 & 7.14 & $3.52 \%$ & $2.86 \%$ & $-5.56 \%$ & \multirow{2}{*}{$5.21 \%$} & \multirow{2}{*}{$-3.27 \%$} & \multirow{2}{*}{$-0.40 \%$} & \multirow{2}{*}{$0.56 \%$} & 7.23 & 7.35 & 0.21 \\
\hline & $\mathrm{BH} 011$ & 7.47 & 7.11 & 7.53 & 7.18 & $-4.82 \%$ & $5.91 \%$ & $-4.65 \%$ & & & & & 7.29 & 7.36 & 0.21 \\
\hline \multirow{4}{*}{ PVC } & $\mathrm{BH} 020$ & 5.65 & 5.11 & 5.57 & 5.19 & $-9.56 \%$ & $9.00 \%$ & $-6.82 \%$ & \multirow{2}{*}{$4.07 \%$} & \multirow{2}{*}{$12.13 \%$} & \multirow{2}{*}{$18.67 \%$} & \multirow{2}{*}{$15.61 \%$} & 5.38 & 5.38 & 0.27 \\
\hline & $\mathrm{BH} 021$ & 5.88 & 5.73 & 6.61 & 6.00 & $-2.55 \%$ & $15.36 \%$ & $-9.23 \%$ & & & & & 5.81 & 6.31 & 0.39 \\
\hline & $\mathrm{BH} 030$ & 6.53 & 6.39 & 6.62 & 6.53 & $-2.14 \%$ & $3.60 \%$ & $-1.36 \%$ & \multirow{2}{*}{$6.74 \%$} & \multirow{2}{*}{$5.16 \%$} & \multirow{2}{*}{$5.44 \%$} & \multirow{2}{*}{$0.00 \%$} & 6.46 & 6.58 & 0.10 \\
\hline & $\mathrm{BH} 031$ & 6.97 & 6.72 & 6.98 & 6.53 & $-3.59 \%$ & $3.87 \%$ & $-6.45 \%$ & & & & & 6.85 & 6.76 & 0.22 \\
\hline \multirow{4}{*}{ PUAM } & $\mathrm{BH} 040$ & 5.69 & 5.68 & 6.20 & 5.76 & $-0.18 \%$ & $9.15 \%$ & $-7.10 \%$ & \multirow{2}{*}{$5.10 \%$} & \multirow{2}{*}{$10.56 \%$} & \multirow{2}{*}{$18.39 \%$} & \multirow{2}{*}{$2.78 \%$} & 5.69 & 5.98 & 0.25 \\
\hline & $\mathrm{BH} 041$ & 5.98 & 6.28 & 7.34 & 5.92 & $5.02 \%$ & $16.88 \%$ & $-19.35 \%$ & & & & & 6.13 & 6.63 & 0.66 \\
\hline & $\mathrm{BH} 050$ & 6.11 & 5.73 & 5.86 & 6.24 & $-6.22 \%$ & $2.27 \%$ & $6.48 \%$ & \multirow{2}{*}{$6.55 \%$} & \multirow{2}{*}{$4.19 \%$} & \multirow{2}{*}{$3.07 \%$} & \multirow{2}{*}{$3.85 \%$} & 5.92 & 6.05 & 0.23 \\
\hline & $\mathrm{BH} 051$ & 6.51 & 5.97 & 6.04 & 6.48 & $-8.29 \%$ & $1.17 \%$ & $7.28 \%$ & & & & & 6.24 & 6.26 & 0.28 \\
\hline
\end{tabular}

PEB - Parque Ecológico do Brejinho; PVC - Parque Vila Clóris; PUAM - Parque Ursulina de Andrade Mello. 
Tabela 2: Resultados de $\mathrm{CaCO}_{3}$.

\begin{tabular}{|c|c|c|c|c|c|c|c|c|c|c|c|c|c|c|c|}
\hline \multirow[b]{2}{*}{ Parque } & \multirow[b]{2}{*}{ AMOSTRA } & \multicolumn{4}{|c|}{ Alcalinidade (mg/L CaCO3) } & \multicolumn{3}{|c|}{ Variação (\%) } & \multicolumn{4}{|c|}{$\begin{array}{c}\text { Variação entre nascentes e } \\
\text { cursos d’água (\%) }\end{array}$} & \multicolumn{2}{|c|}{ Média aritmética } & \multirow{2}{*}{$\begin{array}{c}\text { Desvio padrão } \\
\text { Amostra }\end{array}$} \\
\hline & & jun/18 & set/18 & dez/18 & mar/19 & jun/set & set/dez & dez/mar & jun/18 & set/18 & dez/18 & $\operatorname{mar} / 19$ & $\begin{array}{c}\text { Estação } \\
\text { seca } \\
\text { (jun/set) }\end{array}$ & $\begin{array}{c}\text { Estação } \\
\text { úmida } \\
\text { (dez/mar) }\end{array}$ & \\
\hline \multirow{2}{*}{ PEB } & $\mathrm{BH} 010$ & 194.00 & 197.00 & - & 196.00 & $1.55 \%$ & - & - & \multirow{2}{*}{$-43.81 \%$} & \multirow{2}{*}{$-48.22 \%$} & \multirow{2}{*}{ - } & \multirow{2}{*}{ - } & 195.50 & - & 1.25 \\
\hline & $\mathrm{BH} 011$ & 109.00 & 102.00 & 127.00 & - & $-6.42 \%$ & $24.51 \%$ & - & & & & & 105.50 & - & 10.53 \\
\hline \multirow{4}{*}{ PVC } & $\mathrm{BH} 020$ & 23.00 & 9.00 & 13.00 & 13.00 & $-60.87 \%$ & $44.44 \%$ & $0.00 \%$ & \multirow{2}{*}{$0.00 \%$} & \multirow{2}{*}{$111.11 \%$} & \multirow{2}{*}{$153.85 \%$} & \multirow{2}{*}{$130.77 \%$} & 16.00 & 13.00 & 5.17 \\
\hline & $\mathrm{BH} 021$ & 23.00 & 19.00 & 33.00 & 30.00 & $-17.39 \%$ & $73.68 \%$ & $-9.09 \%$ & & & & & 21.00 & 31.50 & 5.54 \\
\hline & $\mathrm{BH} 030$ & 114.00 & 96.00 & 86.00 & 120.00 & $-15.79 \%$ & $-10.42 \%$ & $39.53 \%$ & \multirow{2}{*}{$15.79 \%$} & \multirow{2}{*}{$10.42 \%$} & \multirow{2}{*}{$12.79 \%$} & \multirow{2}{*}{$9.17 \%$} & 105.00 & 103.00 & 13.64 \\
\hline & $\mathrm{BH} 031$ & 132.00 & 106.00 & 97.00 & 131.00 & $-19.70 \%$ & $-8.49 \%$ & $35.05 \%$ & & & & & 119.00 & 114.00 & 15.34 \\
\hline \multirow{4}{*}{ PUAM } & $\mathrm{BH} 040$ & 25.00 & 19.00 & 19.00 & 28.00 & $-24.00 \%$ & $0.00 \%$ & $47.37 \%$ & \multirow{2}{*}{$-4.00 \%$} & \multirow{2}{*}{$31.58 \%$} & \multirow{2}{*}{$421.05 \%$} & \multirow{2}{*}{$3.57 \%$} & 22.00 & 23.50 & 3.90 \\
\hline & $\mathrm{BH} 041$ & 24.00 & 25.00 & 99.00 & 29.00 & $4.17 \%$ & $296.00 \%$ & $-70.71 \%$ & & & & & 24.50 & 64.00 & 31.67 \\
\hline & $\mathrm{BH} 050$ & 14.00 & 25.00 & 37.00 & 13.00 & $78.57 \%$ & $48.00 \%$ & $-64.86 \%$ & \multirow{2}{*}{$-50.00 \%$} & \multirow{2}{*}{$8.00 \%$} & \multirow{2}{*}{$-8.11 \%$} & \multirow{2}{*}{$661.54 \%$} & 19.50 & 25.00 & 9.73 \\
\hline & $\mathrm{BH} 051$ & 7.00 & 27.00 & 34.00 & 99.00 & $285.71 \%$ & $25.93 \%$ & $191.18 \%$ & & & & & 17.00 & 66.50 & 34.51 \\
\hline
\end{tabular}

PEB - Parque Ecológico do Brejinho; PVC - Parque Vila Clóris; PUAM - Parque Ursulina de Andrade Mello

Obs.: os campos em branco representam valores anômalos (extremamente elevados) que foram descartados por não apresentarem relação com os valores de $\mathrm{pH}$ (possível contaminação dos frascos de coleta).

Tabela 3: Resultados de C.E.

\begin{tabular}{|c|c|c|c|c|c|c|c|c|c|c|c|c|c|c|c|}
\hline \multirow{3}{*}{ Parque } & AMOSTRA & \multicolumn{4}{|c|}{ CE $(\mu \mathrm{S} / \mathrm{cm})$} & \multicolumn{3}{|c|}{ Variação (\%) } & \multicolumn{3}{|c|}{ Variação entre nascentes e } \\
cursos d’água (\%)
\end{tabular}

PEB - Parque Ecológico do Brejinho; PVC - Parque Vila Clóris; PUAM - Parque Ursulina de Andrade Mello.

Tabela 4: Resultados de STD.

\begin{tabular}{|c|c|c|c|c|c|c|c|c|c|c|c|c|c|c|c|}
\hline \multirow[b]{2}{*}{ Parque } & \multirow[b]{2}{*}{ AMOSTRA } & \multicolumn{4}{|c|}{ STD (mg/L) } & \multicolumn{3}{|c|}{ Variação (\%) } & \multicolumn{4}{|c|}{$\begin{array}{c}\text { Variação entre nascentes e } \\
\text { cursos d’água }(\%)\end{array}$} & \multicolumn{2}{|c|}{ Média aritmética } & \multirow{2}{*}{\begin{tabular}{|c} 
Desvio padrão \\
Amostra
\end{tabular}} \\
\hline & & jun/18 & set/18 & dez/18 & mar/19 & jun/set & set/dez & dez/mar & jun/18 & set/18 & dez/18 & mar/19 & $\begin{array}{c}\text { Estação } \\
\text { seca } \\
\text { (jun/set) }\end{array}$ & $\begin{array}{c}\text { Estação } \\
\text { úmida } \\
\text { (dez/mar) }\end{array}$ & \\
\hline \multirow{2}{*}{ PEB } & $\mathrm{BH} 010$ & 281.00 & 453.00 & 245.00 & - & $61.21 \%$ & $-45.92 \%$ & - & \multirow{2}{*}{$-28.11 \%$} & \multirow{2}{*}{$-19.21 \%$} & \multirow{2}{*}{$-24.49 \%$} & \multirow{2}{*}{-} & 367.00 & - & 111.16 \\
\hline & $\mathrm{BH} 011$ & 202.00 & 366.00 & 185.00 & - & $81.19 \%$ & $-49.45 \%$ & - & & & & & 284.00 & - & 99.95 \\
\hline \multirow{4}{*}{ PVC } & $\mathrm{BH} 020$ & 273.00 & 250.00 & 123.00 & - & $-8.42 \%$ & $-50.80 \%$ & - & \multirow{2}{*}{$1.10 \%$} & \multirow{2}{*}{$0.00 \%$} & \multirow{2}{*}{$19.51 \%$} & \multirow{2}{*}{-} & 261.50 & - & 80.79 \\
\hline & $\mathrm{BH} 021$ & 276.00 & 250.00 & 147.00 & - & \begin{tabular}{|l|}
$-9.42 \%$ \\
\end{tabular} & $-41.20 \%$ & - & & & & & 263.00 & - & 68.22 \\
\hline & $\mathrm{BH} 030$ & 173.00 & 147.00 & 100.00 & - & $-15.03 \%$ & $-31.97 \%$ & - & \multirow{2}{*}{$16.76 \%$} & \multirow{2}{*}{$22.45 \%$} & \multirow{2}{*}{$6.00 \%$} & \multirow[t]{2}{*}{ - } & 160.00 & - & 37.00 \\
\hline & $\mathrm{BH} 031$ & 202.00 & 180.00 & 106.00 & - & $-10.89 \%$ & $-41.11 \%$ & - & & & & & 191.00 & - & 50.29 \\
\hline \multirow{4}{*}{ PUAM } & $\mathrm{BH} 040$ & 216.00 & 144.00 & 77.00 & - & $-33.33 \%$ & $-46.53 \%$ & - & \multirow{2}{*}{$-12.50 \%$} & \multirow{2}{*}{$-12.50 \%$} & \multirow{2}{*}{$70.13 \%$} & \multirow{2}{*}{ - } & 180.00 & - & 69.51 \\
\hline & $\mathrm{BH} 041$ & 189.00 & 126.00 & 131.00 & - & $-33.33 \%$ & $3.97 \%$ & - & & & & & 157.50 & - & 35.02 \\
\hline & $\mathrm{BH} 050$ & 109.00 & 155.00 & 99.00 & - & $42.20 \%$ & $-36.13 \%$ & - & \multirow{2}{*}{$-2.75 \%$} & \multirow{2}{*}{$3.87 \%$} & \multirow{2}{*}{$-3.03 \%$} & \multirow[b]{2}{*}{-} & 132.00 & - & 29.87 \\
\hline & $\mathrm{BH} 051$ & 106.00 & 161.00 & 96.00 & - & $51.89 \%$ & $-40.37 \%$ & - & & & & & 133.50 & - & 35.00 \\
\hline
\end{tabular}

PEB - Parque Ecológico do Brejinho; PVC - Parque Vila Clóris; PUAM - Parque Ursulina de Andrade Mello.

Obs.: os dados de março foram excluídos por provável erro analítico e, portanto, não há como calcular a variação percentual e a média aritmética da estação úmida. 
Tabela 5: Resultados de DBO.

\begin{tabular}{|c|c|c|c|c|c|c|c|}
\hline \multirow[t]{2}{*}{ Parque } & \multirow[t]{2}{*}{ AMOSTRA } & \multicolumn{2}{|c|}{$\mathrm{DBO}(\mathrm{mg} / \mathrm{L})$} & \multirow{2}{*}{$\begin{array}{c}\begin{array}{c}\text { Variação entre } \\
\text { campanhas (\%) }\end{array} \\
\text { set/mar }\end{array}$} & \multicolumn{2}{|c|}{$\begin{array}{c}\text { Variação entre } \\
\text { nascentes e cursos } \\
\text { d’água }(\%) \\
\end{array}$} & \multirow{2}{*}{$\begin{array}{c}\text { Desvio padrão } \\
\text { Amostra }\end{array}$} \\
\hline & & set/18 & $\mathrm{mar} / 19$ & & set/18 & $\mathrm{mar} / 19$ & \\
\hline \multirow{2}{*}{ PEB } & $\mathrm{BH} 010$ & 5.20 & 1.75 & $-66.35 \%$ & \multirow{2}{*}{$18.08 \%$} & \multirow{2}{*}{$145.71 \%$} & 2.44 \\
\hline & BH011 & 6.14 & 4.30 & $-29.97 \%$ & & & 1.30 \\
\hline \multirow{4}{*}{ PVC } & $\mathrm{BH} 020$ & 4.51 & 1.27 & $-71.84 \%$ & \multirow{2}{*}{$35.25 \%$} & \multirow{2}{*}{ - } & 2.29 \\
\hline & $\mathrm{BH} 021$ & 6.10 & - & - & & & - \\
\hline & $\mathrm{BH} 030$ & - & 1.00 & - & \multirow{2}{*}{ - } & \multirow{2}{*}{ - } & - \\
\hline & $\mathrm{BH} 031$ & 5.17 & - & - & & & - \\
\hline \multirow{4}{*}{ PUAM } & $\mathrm{BH} 040$ & 3.74 & 1.02 & $-72.73 \%$ & \multirow{2}{*}{$36.90 \%$} & \multirow{2}{*}{$56.86 \%$} & 1.92 \\
\hline & $\mathrm{BH} 041$ & 5.12 & 1.60 & $-68.75 \%$ & & & 2.49 \\
\hline & $\mathrm{BH} 050$ & 4.39 & - & - & \multirow{2}{*}{ - } & \multirow{2}{*}{ - } & - \\
\hline & BH051 & - & - & - & & & - \\
\hline
\end{tabular}

PEB - Parque Ecológico do Brejinho; PVC - Parque Vila Clóris; PUAM - Parque Ursulina de Andrade Mello.

Tabela 6: Resultados de Sulfatos.

\begin{tabular}{|c|c|c|c|c|c|c|c|c|c|c|c|c|c|c|c|}
\hline \multirow[b]{2}{*}{ Parque } & \multirow[b]{2}{*}{ AMOSTRA } & \multicolumn{4}{|c|}{ Sulfato (mg/L) } & \multicolumn{3}{|c|}{ Variação (\%) } & \multicolumn{4}{|c|}{$\begin{array}{l}\text { Variação entre nascentes e } \\
\text { cursos d'água (\%) }\end{array}$} & \multicolumn{2}{|c|}{ Média aritmética } & \multirow{2}{*}{$\begin{array}{c}\text { Desvio padrão } \\
\text { Amostra }\end{array}$} \\
\hline & & jun $/ 18$ & set/18 & dez/18 & mar/19 & jun/set & set/dez & dez/mar & jun/18 & set/18 & dez/18 & $\mathrm{mar} / 19$ & $\begin{array}{c}\text { Estação } \\
\text { seca } \\
\text { (jun/set) }\end{array}$ & $\begin{array}{l}\text { Estação } \\
\text { úmida } \\
\text { (dez/mar) }\end{array}$ & \\
\hline \multirow{2}{*}{ PEB } & $\mathrm{BH} 010$ & 2.73 & 3.3 & 2.3 & 2.6 & $20.88 \%$ & $-30.30 \%$ & $13.04 \%$ & \multirow{2}{*}{$15.38 \%$} & \multirow{2}{*}{$12.12 \%$} & \multirow{2}{*}{$47.83 \%$} & \multirow{2}{*}{$30.77 \%$} & 3.02 & 2.45 & 0.42 \\
\hline & $\mathrm{BH} 011$ & 3.15 & 3.7 & 3.4 & 3.4 & $17.46 \%$ & $-8.11 \%$ & $0.00 \%$ & & & & & 3.43 & 3.40 & 0.23 \\
\hline \multirow{4}{*}{ PVC } & $\mathrm{BH} 020$ & 2.05 & 2 & 2.9 & 3.4 & $-2.44 \%$ & $45.00 \%$ & $17.24 \%$ & \multirow{2}{*}{$40.00 \%$} & \multirow{2}{*}{$50.00 \%$} & \multirow{2}{*}{$41.38 \%$} & \multirow{2}{*}{$32.35 \%$} & 2.03 & 3.15 & 0.68 \\
\hline & $\mathrm{BH} 021$ & 2.87 & 3 & 4.1 & 4.5 & $4.53 \%$ & $36.67 \%$ & $9.76 \%$ & & & & & 2.94 & 4.30 & 0.81 \\
\hline & $\mathrm{BH} 030$ & 3.83 & 4.1 & 8.1 & 3.3 & $7.05 \%$ & $97.56 \%$ & $-59.26 \%$ & \multirow{2}{*}{$-46.48 \%$} & \multirow{2}{*}{$-51.22 \%$} & \multirow{2}{*}{$-50.62 \%$} & \multirow{2}{*}{$-6.06 \%$} & 3.97 & 5.70 & 2.20 \\
\hline & $\mathrm{BH} 031$ & 2.05 & 2 & 4 & 3.1 & $-2.44 \%$ & $100.00 \%$ & $-22.50 \%$ & & & & & 2.03 & 3.55 & 0.95 \\
\hline \multirow{4}{*}{ PUAM } & $\mathrm{BH} 040$ & 3.01 & 4 & 3.4 & 6.6 & $32.89 \%$ & $-15.00 \%$ & $94.12 \%$ & \multirow{2}{*}{$-22.92 \%$} & \multirow{2}{*}{$20.00 \%$} & \multirow{2}{*}{$85.29 \%$} & \multirow{2}{*}{$-36.36 \%$} & 3.51 & 5.00 & 1.62 \\
\hline & $\mathrm{BH} 041$ & 2.32 & 4.8 & 6.3 & 4.2 & $106.90 \%$ & $31.25 \%$ & $-33.33 \%$ & & & & & 3.56 & 5.25 & 1.65 \\
\hline & $\mathrm{BH} 050$ & 4.66 & 2 & 13.4 & 14.7 & $-57.08 \%$ & $570.00 \%$ & $9.70 \%$ & \multirow{2}{*}{$-85.41 \%$} & \multirow{2}{*}{$30.00 \%$} & \multirow{2}{*}{$14.93 \%$} & \multirow{2}{*}{$-71.43 \%$} & 3.33 & 14.05 & 6.31 \\
\hline & $\mathrm{BH} 051$ & 0.68 & 2.6 & 15.4 & 4.2 & $282.35 \%$ & $492.31 \%$ & $-72.73 \%$ & & & & & 1.64 & 9.80 & 6.61 \\
\hline
\end{tabular}

PEB - Parque Ecológico do Brejinho; PVC - Parque Vila Clóris; PUAM - Parque Ursulina de Andrade Mello.

Tabela 7: Resultados de Cálcio.

\begin{tabular}{|c|c|c|c|c|c|c|c|c|c|c|c|c|c|c|c|}
\hline \multirow[b]{2}{*}{ Parque } & \multirow[b]{2}{*}{ AMOSTRA } & \multicolumn{4}{|c|}{$\mathrm{Ca} 2+\quad(\mathrm{mg} / \mathrm{L})$} & \multicolumn{3}{|c|}{ Variação $(\mathrm{mg} / \mathrm{L})^{*}$} & \multicolumn{4}{|c|}{$\begin{array}{l}\text { Variação entre nascentes e } \\
\text { cursos d'água }(\mathrm{mg} / \mathrm{L})^{*}\end{array}$} & \multicolumn{2}{|c|}{ Média aritmética } & \multirow{2}{*}{$\begin{array}{c}\text { Desvio padrão } \\
\text { Amostra }\end{array}$} \\
\hline & & jun/18 & set/18 & dez/18 & mar/19 & jun/set & set/dez & dez/mar & jun/18 & set/18 & dez/18 & mar/19 & $\begin{array}{c}\text { Estação } \\
\text { seca } \\
\text { (jun/set) }\end{array}$ & $\begin{array}{c}\text { Estação } \\
\text { úmida } \\
\text { (dez/mar) }\end{array}$ & \\
\hline \multirow{2}{*}{ PEB } & $\mathrm{BH} 010$ & 59.30 & 1.90 & 3.50 & 3.80 & -57.40 & 1.60 & 0.30 & \multirow{2}{*}{-20.80} & \multirow{2}{*}{-1.10} & \multirow{2}{*}{-1.60} & \multirow{2}{*}{-0.10} & 30.60 & 3.65 & 24.36 \\
\hline & $\mathrm{BH} 011$ & 38.50 & 0.80 & 1.90 & 3.70 & -37.70 & 1.10 & 1.80 & & & & & 19.65 & 2.80 & 15.78 \\
\hline \multirow{4}{*}{ PVC } & $\mathrm{BH} 020$ & 9.60 & 0.40 & 0.20 & 1.90 & -9.20 & -0.20 & 1.70 & \multirow{2}{*}{0.00} & \multirow{2}{*}{-0.30} & \multirow{2}{*}{0.40} & \multirow{2}{*}{-0.20} & 5.00 & 1.05 & 3.85 \\
\hline & $\mathrm{BH} 021$ & 9.60 & 0.10 & 0.60 & 1.70 & -9.50 & 0.50 & 1.10 & & & & & 4.85 & 1.15 & 3.85 \\
\hline & $\mathrm{BH} 030$ & 19.20 & 0.40 & 0.90 & 2.90 & -18.80 & 0.50 & 2.00 & \multirow{2}{*}{17.70} & \multirow{2}{*}{-0.30} & \multirow{2}{*}{0.20} & \multirow{2}{*}{0.30} & 9.80 & 1.90 & 7.76 \\
\hline & $\mathrm{BH} 031$ & 36.90 & 0.10 & 1.10 & 3.20 & -36.80 & 1.00 & 2.10 & & & & & 18.50 & 2.15 & 15.38 \\
\hline \multirow{4}{*}{ PUAM } & $\mathrm{BH} 040$ & 9.60 & 0.10 & 0.10 & 1.70 & -9.50 & 0.00 & 1.60 & \multirow{2}{*}{0.00} & \multirow{2}{*}{0.00} & \multirow{2}{*}{1.10} & \multirow{2}{*}{0.00} & 4.85 & 0.90 & 3.94 \\
\hline & $\mathrm{BH} 041$ & 9.60 & 0.10 & 1.20 & 1.70 & -9.50 & 1.10 & 0.50 & & & & & 4.85 & 1.45 & 3.77 \\
\hline & $\mathrm{BH} 050$ & 0.00 & 0.20 & 0.80 & 1.20 & 0.20 & 0.60 & 0.40 & \multirow{2}{*}{0.00} & \multirow{2}{*}{0.10} & \multirow{2}{*}{-0.20} & \multirow{2}{*}{1.50} & 0.10 & 1.00 & 0.48 \\
\hline & $\mathrm{BH} 051$ & 0.00 & 0.30 & 0.60 & 2.70 & 0.30 & 0.30 & 2.10 & & & & & 0.15 & 1.65 & 1.06 \\
\hline
\end{tabular}

*Resultados em valores absolutos devido ao registro do valor igual a zero das amostras BH050-051 em jun/2018.

PEB - Parque Ecológico do Brejinho; PVC - Parque Vila Clóris; PUAM - Parque Ursulina de Andrade Mello. 
Tabela 8: Resultados de Magnésio.

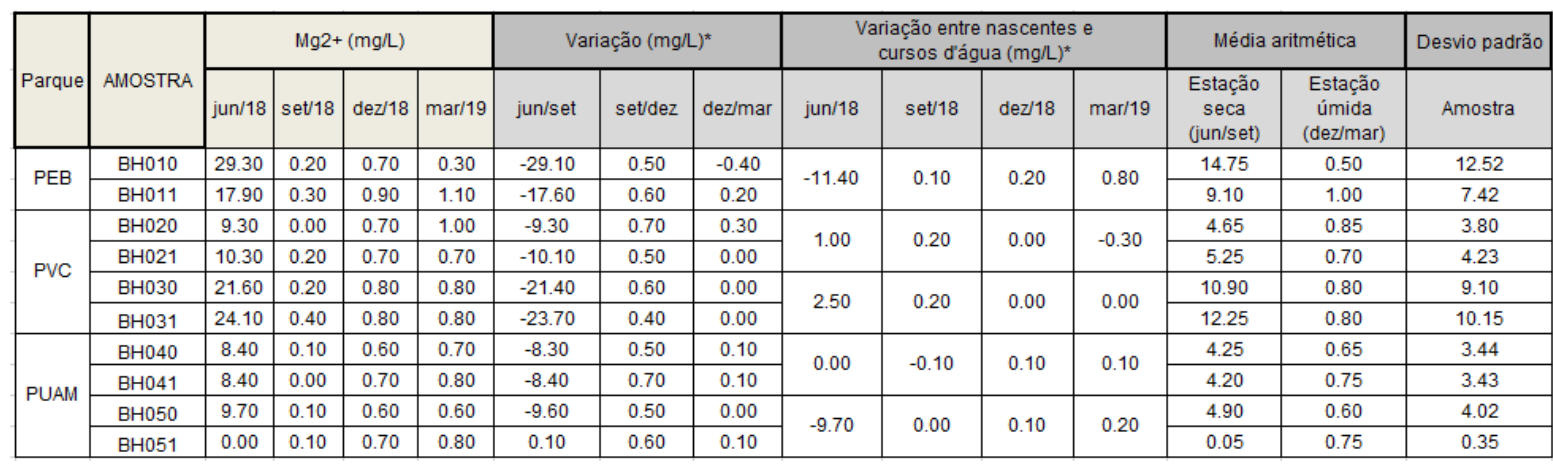

*Resultados em valores absolutos devido ao registro do valor igual a zero da amostra BH051 em jun/2018. PEB - Parque Ecológico do Brejinho; PVC - Parque Vila Clóris; PUAM - Parque Ursulina de Andrade Mello.

Tabela 9: Resultados de Potássio.

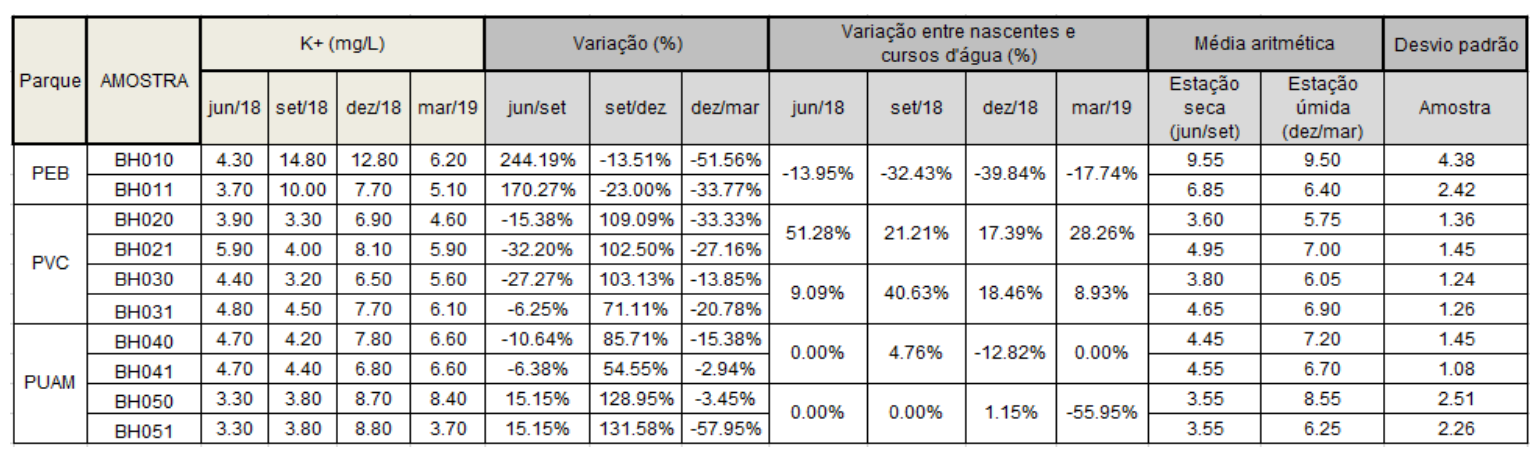

PEB - Parque Ecológico do Brejinho; PVC - Parque Vila Clóris; PUAM - Parque Ursulina de Andrade Mello.

Tabela 10: Resultados de Sódio.

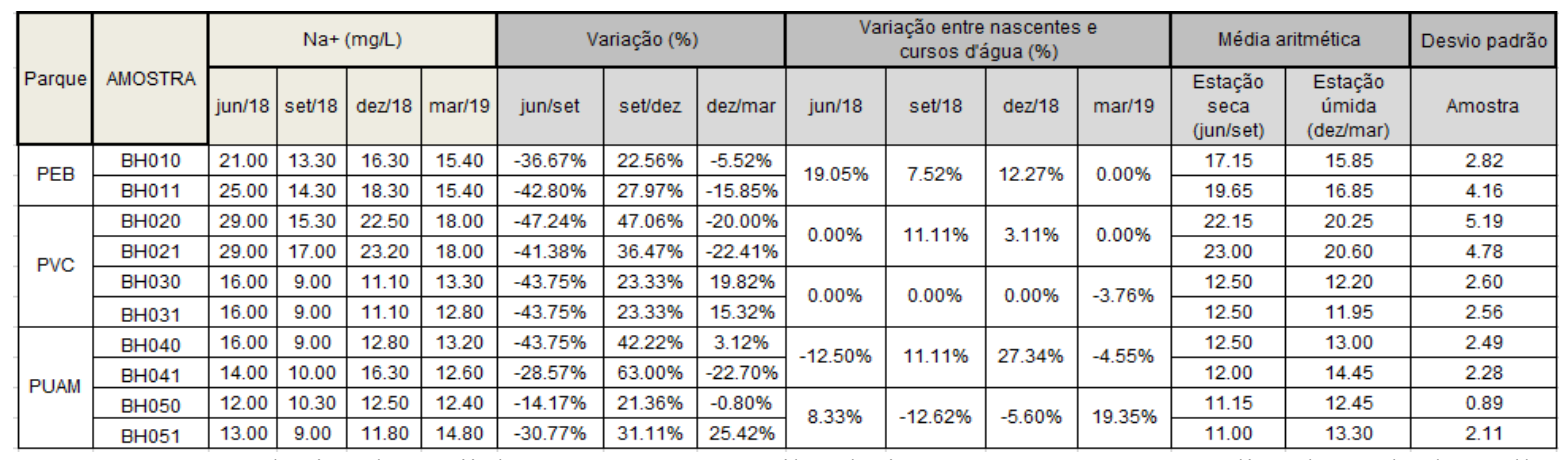

PEB - Parque Ecológico do Brejinho; PVC - Parque Vila Clóris; PUAM - Parque Ursulina de Andrade Mello.

\subsection{Parque Ecológico do Brejinho (PEB)}

\subsubsection{Potencial Hidrogeniônico $(\mathrm{pH})$ e Alcalinidade $\left(\mathrm{CaCO}_{3}\right)$}

Como os parâmetros pH e alcalinidade são diretamente relacionados, serão analisados em conjunto. $\mathrm{O}$ pH sinaliza a variação da concentração do íon hidrônio $\left[\mathrm{H}_{3} \mathrm{O}+(\mathrm{aq})\right]$ em soluções. Os menores valores de $\mathrm{pH}$ podem refletir a presença de matéria orgânica nos ambientes brejosos, enquanto que os valores mais básicos podem indicar efeitos antrópicos como poluentes saponáceos. As amostras do Parque Ecológico Brejinho (PEB) apresentam valores acima de 7 sendo que, em 
termos sazonais, não foi verificado um comportamento padrão do $\mathrm{pH}$ dos pontos estudados, fato que pode estar relacionado ao efeito redutor dos ambientes brejosos (Tab. 1).

A maioria dos sistemas analisados apresenta aumento de $\mathrm{pH}$, ainda que irrisório, entre as nascentes e os cursos d'água, denotando ligeira alcalinização. Esse fato se deve à maior oxigenação das águas após a concentração dos fluxos, que degrada parcialmente os compostos orgânicos gerados nos ambientes redutores helocreno e hipocreno. Dentre as nascentes e os cursos d'água, os sistemas do PEB mostram uma redução significativa dos valores em junho e setembro.

Já os maiores valores de alcalinidade refletem a presença de minerais carbonatados e bicarbonatados dissolvidos de rochas e formações superficiais, como a calcita (CaCO3). O PEB apresenta pouca variação nos dados da nascente BH010, enquanto que no BH011 há tendência de aumento entre junho e dezembro (Tab. 2).

\subsubsection{Condutividade Elétrica (C.E.) e Sólidos Totais Dissolvidos (STD)}

Os valores de condutividade elétrica (CE) foram significativamente elevados neste parque em ambas as estações (entre 300 e $490 \mu \mathrm{S} / \mathrm{cm}$ ), apresentando os maiores valores do conjunto amostral e podendo indicar o papel da matéria orgânica nos ambientes brejosos (Tab. 3). Em termos de rede hidrográfica, o sistema do PEB mostra a redução de valores de concentração de sais por volume de água da nascente para o curso d'água, em todos os períodos de análise, indicando o aumento natural das vazões em direção à jusante. No ponto BH011, a CE apresenta comportamento inverso ao da alcalinidade e do $\mathrm{pH}$, ou seja, a redução em dezembro e o aumento em março.

Conforme a Tabela 4 os valores de STD são relativamente elevados para junho, setembro e dezembro, atingindo, em setembro, 453 e 366 mg/l nos pontos BH010 e BH011, respectivamente. Esse fato indica uma mobilização de sólidos dissolvidos proporcionalmente maior do que o aumento de vazão. Entre setembro e dezembro, praticamente todos os pontos mostram redução de valores. Já em termos de rede hidrográfica, entre junho e setembro houve aumento de STD nos sistemas do PEB. Desse modo, não houve padrão de comportamento que refletisse a dinâmica variável das chuvas no período (forte elevação entre setembro e dezembro de 2018).

\subsubsection{Demanda Bioquímica de Oxigênio (DBO)}

Devido à impossibilidade de coleta de amostras de água nos $30 \mathrm{~cm}$ de profundidade recomendados para resultados confiáveis, foram consideradas, para as análises de DBO, apenas as campanhas de setembro (final da estação seca) e março (final da estação chuvosa). Ainda assim, somente o PEB apresentou condições para coleta em ambos os pontos. O panorama dos dados mostra uma tendência geral de redução da DBO entre setembro e março, e um aumento 
generalizado entre as nascentes e os cursos d'água (Tab. 5). Este quadro é condicionado pelas abundantes chuvas desse período, no consequente aumento de vazões e na diluição de poluentes, além dos processos naturais de decomposição da matéria orgânica nos ambientes brejosos favorecendo a redução de oxigênio dissolvido e o aumento da DBO. Por outro lado, a forte variação da DBO da nascente BH010 entre as duas campanhas, e o aumento entre essa nascente e o curso d'água, principalmente em março, também refletem a poluição superficial do local, dado o elevado grau de antropização do parque, fato perceptível macroscopicamente pelo aumento da quantidade de lixo entre as campanhas.

\subsubsection{Sulfatos $\left(\mathrm{SO}_{4}{ }^{2-}\right)$}

Os valores de sulfatos são relativamente elevados e indicam os efeitos da poluição superficial no PEB, principalmente em dezembro quando as chuvas mobilizam os poluentes superficiais. Os demais valores se situam na faixa de 2 a 4,5 mg/l (Tab. 6). O parque, por sua vez, mostra as menores variações percentuais, com manutenção dos valores entre dezembro e março, denotando o cenário relativamente constante de efeitos da poluição superficial. Já em termos de conexões hidrográficas, o sistema do Brejinho apresenta pequeno aumento da concentração de sulfatos entre a nascente e o curso d'água, em todos os períodos.

\subsubsection{Cálcio $\left(\mathrm{Ca}^{2+}\right)$ e Magnésio $\left(\mathrm{Mg}^{2+}\right)$}

Verifica-se uma forte variação sazonal das concentrações de cálcio e de magnésio na maioria dos pontos (Tab. 7 e 8). No período chuvoso, somente a amostra BH011, coletada em março, que apresenta a concentração de $\mathrm{Mg}^{2+}$ superior a $1 \mathrm{mg} / 1(1,1)$. Já no caso do $\mathrm{Ca}^{2+}$ os valores são inferiores a 3,8 mg/l (BH010). De modo comparativo, as maiores concentrações ocorrem em junho no Brejinho e no Vila Clóris, em nascentes e cursos d'água. A queda entre junho e setembro atinge quase $100 \%$ em todos os pontos, sendo este cenário esperado pois os valores acompanham a dinâmica pluviométrica - aumento de concentrações na estiagem - e devido ao fato de que tais cátions são provenientes das bases litológica e pedológica que estruturam os hidrossistemas. Por esse motivo, entre setembro e dezembro, quando houve o aumento das precipitações, as concentrações sofreram fortes elevações que chegam a $600 \%$ para o $\mathrm{Mg}^{2+}$ e $1100 \%$ para o $\mathrm{Ca}^{2+}$. No comparativo de dezembro e março o comportamento do $\mathrm{Mg}^{2+}$ é variado, com elevações (inferiores a $43 \%$ ), reduções (57\% no BH010) e também estagnação de concentrações.

A análise das conexões hidrográficas mostra que houve redução da concentração de $\mathrm{Mg}^{2+}$ em junho, entre a nascente e o curso d'água, porém apresenta aumento no período chuvoso. Por sua 
vez, o $\mathrm{Ca}^{2+}$ demonstra redução em todos os quatro períodos, podendo indicar retenção geoquímica nas formações superficiais.

\subsubsection{Potássio $\left(\mathrm{K}^{+}\right)$e Sódio $\left(\mathrm{Na}^{+}\right)$}

Os valores mais elevados de $\mathrm{K}^{+}$são da nascente BH010, em setembro e dezembro: 14,8 e 12,8 mg/l, respectivamente (Tab. 9). Já o período de junho a setembro mostra as maiores variações percentuais dos dados de todo o conjunto amostral: 244\% de aumento na nascente (BH010) e 170\% no curso d'água (BH011). Esse padrão difere do verificado nos demais Parques, cujos dados mostram a redução das concentrações entre junho e setembro - com exceção do sistema BH050051.

Já os valores de $\mathrm{Na}^{+}$apresentam tendência de redução em setembro, em todos os parques, sobretudo no PEB (Tab. 10). Esse comportamento difere da elevação do $\mathrm{K}^{+}$entre junho e setembro; considerando também que as concentrações de $\mathrm{K}^{+}$no PEB caem entre a nascente e o curso d'água, em todos os períodos. Os valores de $\mathrm{Na}^{+}$mostram uma tendência contrária, ou seja, o aumento em todos os períodos, com exceção de março, em que os valores permanecem constantes. Esse quadro pode indicar a maior eficiência das formações superficiais orgânicas na retenção do $\mathrm{K}^{+}$do que do $\mathrm{Na}^{+}$, assim como o maior enriquecimento desse último em função de poluentes superficiais.

\subsection{Parque Vila Clóris (PVC)}

\subsubsection{Potencial Hidrogeniônico $(\mathrm{pH})$ e Alcalinidade $\left(\mathrm{CaCO}_{3}\right)$}

Os valores de pH não apresentam significativa diferenciação, situando-se entre 5,11 e 6,98 ao longo do ano hidrológico - apresentando apenas certa elevação de valores em dezembro (Tab.1). No tocante à alcalinidade, a nascente brejosa BH020 apresenta o pico de valores no período seco (junho), mas o curso d'água (BH021) mostra tendência contrária: picos em dezembro e março (Tab.2). Já o sistema BH030-031 apresenta, como no PEB, os maiores valores do conjunto amostral, com destaque para junho e março. Essas diferenças devem resultar de fatores superficiais, já que não há diferenças litológicas mapeadas no substrato de ambos os sistemas. O sistema BH020021 está próximo à uma rua, apresentando lixo na vertente que integra a bacia de contribuição da nascente, na maioria das campanhas de campo. Já o sistema BH030-031 está mais afastado dos limites do parque e em área sem a presença de lixo. Por outro lado, os dois sistemas mostram uma tendência geral de aumento dos valores entre as nascentes e os cursos d'água, em todos os períodos, com destaque para o BH020-021 entre setembro e março. Essa tendência pode ser refletida, portanto, pelos agravantes efeitos da poluição superficial.

\subsubsection{Condutividade Elétrica (C.E.) e Sólidos Totais Dissolvidos (STD)}


Sobre os resultados de CE, percebe-se uma tendência geral de queda até dezembro/2018 e um considerável aumento em março/2019, exceto para o ponto BH021 que apresentou elevação de 20,54\% já em dez./2018 (Tab.3). Ademais, os dados referentes ao STD apresentam uma queda geral em todos os pontos analisados, sendo mais expressiva a queda entre os meses set./2018 e dez./2018, comparativamente (Tab. 4).

O sistema BH030-031 evidencia a redução de valores da nascente para o curso d'água, em todos os períodos, enquanto o sistema BH020-021 apresenta, quase sempre, um aumento dos valores. Esse fato pode ser resultante de poluição superficial e de aparente redução ocasional dos fluxos - como fora verificado em março no ponto BH021, ainda que no final do período chuvoso. No tocante aos valores de STD, nota-se a redução dos valores entre junho e setembro, continuando em dezembro.

\subsubsection{Demanda Bioquímica de Oxigênio (DBO)}

Para a DBO, foi possível coletar amostras apenas no sistema BH020-021 (Tab.5). Houve decréscimo importante dos valores da nascente entre setembro e março $(71,8 \%)$, indicando que as abundantes chuvas do período contrabalancearam o papel da poluição superficial no sistema brejoso. Nesse contexto, houve aumento, em setembro, de 35\% de DBO entre a nascente e o curso d'água.

\subsubsection{Sulfatos $\left(\mathrm{SO}_{4}{ }^{2-}\right)$}

Pelo fato de os valores para Sulfato nos outros Parques situarem-se predominantemente na faixa de 2 a 4,5 mg/l, nota-se um cenário contrastante no PVC. O sistema BH020-021 apresenta um aumento dos valores em todos os períodos, enquanto o BH030-031 mostra tendência contrária de redução em todos os períodos, chegando a cerca de 50\% em setembro e dezembro (Tab.6).

\subsubsection{Cálcio $\left(\mathrm{Ca}^{2+}\right)$ e Magnésio $\left(\mathrm{Mg}^{2+}\right)$}

No PVC, os dados demonstram que a concentração de $\mathrm{Ca}^{2+}$ varia significativamente em todos os pontos de coleta do Parque; apresentando uma considerável queda entre os períodos de jun. e set./2018, certa estabilidade entre set./dez. e um modesto aumento entre dez. e mar./2019. Ademais, verifica-se uma enorme variação da concentração de Cálcio entre as nascentes e cursos d'água no mês de jun./2018 entre os pontos BH030 e BH031 e considerável estabilidade ou curta variação negativa nos demais (conf. Tab. 7). 
No tocante aos dados de $\mathrm{Mg}^{2+}$ do PVC, os dados apontam para a queda de concentração entre os períodos de jun./set. de 2018 e demonstram certa estabilidade de set. à mar./2019. Dentre as variações de dados das nascentes para os cursos d'água, apenas na campanha de jun./2018 que houveram oscilações significativas entre os sistemas BH020-021 e BH030-03, tendo os demais períodos apresentados certa estabilidade (Tab.8).

\subsubsection{Potássio $\left(\mathrm{K}^{+}\right)$e Sódio $\left(\mathrm{Na}^{+}\right)$}

Os maiores valores de $\mathrm{K}^{+}$ocorrem em dezembro, com maiores variações (positivas) entre setembro e dezembro (Tab.9). Os aumentos de concentrações no período chuvoso indicam a influência de poluição superficial nos sistemas do parque.

Os valores de $\mathrm{Na}^{+}$mostram pequenas variações entre os períodos analisados, com picos na estação seca (junho) e na chuvosa (dezembro), seja nas nascentes como nos cursos d'água (Tab.10). Por outro lado, há o aumento da concentração de $\mathrm{K}^{+}$nos dois sistemas, em todos os períodos.

\subsection{Parque Municipal Ursulina de Andrade Mello (PUAM)}

\subsubsection{Potencial Hidrogeniônico $(\mathrm{pH})$ e Alcalinidade $\left(\mathrm{CaCO}_{3}\right)$}

A amostra BH041 possui valores de pH acima de 7,0 (Tab.1), apresentando maior variação de valores entre as campanhas, fato que pode estar associado às oscilações de umidade no ambiente brejoso e à abundante serrapilheira. Em dezembro e março este ponto estava isolado a fim de interromper o acesso de visitantes do parque.

Em termos de alcalinidade, a nascente BH040 apresenta os maiores valores em junho e março e o curso d'água mostra um forte pico em dezembro (+295\% em relação a setembro) Tab.2. Já no sistema BH050-051, a nascente mostra aumento dos valores até dezembro e redução em março. O curso d'água, por sua vez, mostra aumento de $93 \%$ entre junho e março. O parque também se destaca pela forte elevação percentual de alcalinidade em dezembro, no sistema BH40041 (+421\%), e em março, no sistema BH050-051 (+661\%). A elevada concentração de matéria orgânica nos sistemas brejosos pode ter influência direta na redução da alcalinidade. Por outro lado, a forte elevação dos valores entre BH050 e BH051 deve resultar da poluição superficial, pois o sistema é o mais próximo dos limites do parque e pode receber águas pluviais poluídas e resíduos sólidos das cercanias.

\subsubsection{Condutividade Elétrica (C.E.) e Sólidos Totais Dissolvidos (STD)}


Apesar do PUAM apresentar os menores valores absolutos de CE, também concentra as maiores variações percentuais, chegando a 172,5\% de redução no ponto BH041, entre setembro e dezembro, e 85,3\% de aumento no BH050, entre junho e setembro (Tab.3). A falta de estabilidade nos dois sistemas locais indica a maior susceptibilidade aos eventos chuvosos e o rápido feedback dos sistemas em termos de diluição e remoção de sais dissolvidos. Os sistemas apresentaram aumento da CE se comparados os valores das nascentes com os cursos d'água. Esse fato pode advir da poluição superficial, já que se notou um considerável aumento de lixo ao longo das campanhas, particularmente no ponto $\mathrm{BH} 041$.

No sistema BH040-041, ocorreu a redução dos valores de STD entre junho e setembro, tendência que continuou em dezembro (Tab.4). Por outro lado, houve aumento dos valores entre junho e setembro ao longo do sistema BH050-051.

\subsubsection{Demanda Bioquímica de Oxigênio (DBO)}

A DBO pôde ser analisada somente no sistema BH040-041. Ambos os pontos apresentaram os maiores valores de redução da DBO dentre todos os Parques, fato verificado entre setembro e março (Tab.5). Nesse sentido, cabe notar a redução de 68,7\% no BH041, fato que reflete os elevados índices de acumulado pluviométrico entre as campanhas. O padrão de aumento da DBO entre a nascente e o curso d'água, verificado nos outros parques, também se manteve em ambas as campanhas, com maior percentual em março.

\subsubsection{Sulfatos $\left(\mathrm{SO}_{4}{ }^{2-}\right)$}

Os maiores valores foram obtidos nas amostras BH050 (13,4 mg/1 em dezembro e 14,7 $\mathrm{mg} / \mathrm{l} \mathrm{em} \mathrm{março)} \mathrm{e} \mathrm{BH051} \mathrm{(15,4} \mathrm{mg/l} \mathrm{em} \mathrm{dezembro)} \mathrm{-} \mathrm{Tab.} \mathrm{6.} \mathrm{O} \mathrm{ponto} \mathrm{BH051} \mathrm{apresenta} \mathrm{um} \mathrm{aumento}$ de $96 \%$ entre junho $(0,68 \mathrm{mg} / \mathrm{l})$ e dezembro $(15,4 \mathrm{mg} / \mathrm{l})$. Dentre os valores dos outros parques para este parâmetro, as amostras do PUAM resultaram na maior variação percentual, chegando a 106,9\% entre junho e setembro no ponto BH041, 570\% entre setembro e dezembro no BH050 e 282,3\% e 492,3\% no BH051, respectivamente, entre junho/setembro e setembro/dezembro de 2018. Por sua vez, os dois sistemas do PUAM não apresentam constância nos valores, havendo redução em junho e março e aumento entre setembro e dezembro. Estes resultados indicam que as variações de sulfatos respondem mais diretamente à dinâmica temporal de aportes de poluentes (tais como águas pluviais poluídas e/ou esgotos) do quê às variações pluviométricas.

Enquanto o aumento das concentrações nos canais, em relação às nascentes, evidencia o possível papel da poluição, as reduções podem indicar o papel das formações superficiais na retenção de íons, principalmente no período chuvoso (FERREIRA et al., 2018). O aporte hídrico 
nas zonas brejosas favorece o maior contato da água com as formações superficiais orgânicas, podendo levar à retenção geoquímica. Tal fato é evidente no PVC e no PUAM, onde o sistema BH050-051 passa de 4,6 para 0,68 mg/l em junho (- 85\%) e de 14,7 para 4,2 mg/1 em março ($71 \%)$.

\subsubsection{Cálcio $\left(\mathrm{Ca}^{2+}\right)$ e Magnésio $\left(\mathrm{Mg}^{2+}\right)$}

Em menor grau, a mesma tendência de enriquecimento geoquímico que ocorre no período chuvoso no PEB, também ocorre no sistema BH050-051. Em junho, as concentrações são nulas para o $\mathrm{Mg}^{2+}$ no curso d'água e para o $\mathrm{Ca}^{2+}$ na nascente e no curso d'água, aumentando ligeiramente no período chuvoso (Tab. 7 e 8). No caso do $\mathrm{Ca}^{2+}$, houve uma queda expressiva dos valores obtidos dos pontos a partir da segunda campanha de campo (setembro/2018) nos três parques, com exceção do sistema 50-51, o qual obteve um pequeno aumento dos valores registrados. Por outro lado, os dois sistemas do PUAM mostram pouca variação de valores entre as nascentes e os cursos d'água tanto para o Cálcio, quanto para o Magnésio.

\subsubsection{Potássio $\left(\mathrm{K}^{+}\right)$e Sódio $\left(\mathrm{Na}^{+}\right)$}

Neste parque ocorre certa estabilidade no tocante aos valores de concentração de sódio no sistema BH040-041, com exceção de setembro em que há uma evidente redução em relação aos demais períodos. Essa tendência de estabilidade ao longo do tempo, entre as nascentes e os cursos d'água, também é verificada nos sistemas BH050-051 do PUAM - tanto no $\mathrm{Na}^{+}$quanto no $\mathrm{K}^{+}$(Tab. 9 e 10).

\section{REFLEXÕES E CONSIDERAÇÕES FINAIS}

Os resultados reforçam a importância da sazonalidade pluviométrica no comportamento geoquímico dos sistemas hidrográficos estudados. Os períodos chuvosos são acompanhados por frequentes eventos de escoamento pluvial que transportam poluentes acumulados nas superfícies urbanas e deterioram, frequentemente, os sistemas hídricos. As águas de nascentes e cursos d'água podem ser, portanto, fortemente enriquecidas por aportes geoquímicos durante as chuvas. Por outro lado, o fluxo de base, que pereniza e sustenta as vazões, sofre elevados inputs durante a estação chuvosa em função dos rápidos períodos de resposta, dado o relativo menor tempo de residência nos aquíferos superficiais. Já nos períodos de estiagem a redução da recarga dos aquíferos tende a se refletir na redução das vazões e, consequentemente, no aumento da concentração de certos íons, tais como $\mathrm{Mg}^{2+} \mathrm{e} \mathrm{Ca}^{2+}$. Nesse contexto, cabe ressaltar que o comportamento pluviométrico entre junho 
de 2018 e março de 2019 foi irregular dentro da série histórica e demonstra que, para vários parâmetros, as análises não podem ser simplificadas em termos de estações seca e úmida.

O panorama geral dos resultados mostra o papel da poluição urbana no comprometimento da qualidade dos sistemas hídricos nos parques municipais. A cidade de Belo Horizonte reflete a realidade frequente das grandes cidades brasileiras, com frequentes acumulações de lixo e outros poluentes na superfície, mesmo em áreas protegidas, e também deficiências no sistema de saneamento. Problemas de não atendimento ou atendimento deficiente são comuns, e o subdimensionamento ou vazamentos na rede coletora de esgotos trazem, comumente, efeitos de poluição dos sistemas hídricos. As áreas de contribuição pluvial dos pontos analisados apresentam extensão importante fora dos parques, em zonas predominantemente residenciais. Portanto, as possibilidades de poluição dos sistemas hídricos são elevadas nos períodos chuvosos.

Por outro lado, o Parque Ursulina de Mello é o mais conservado, não tendo sido encontrado, visualmente, lixo ou qualquer tipo de poluente nos pontos de amostragem. Esse quadro também deve ser interpretado à luz do grande aporte de matéria orgânica no solo e de cobertura morta provenientes da densa vegetação local (incluindo um bananal). Nos períodos chuvosos, a serrapilheira encharcada propicia a ocorrência dos processos de enriquecimento geoquímico da água, principalmente em ambientes brejosos como nos pontos BH030-031. Ressalta-se, nesse sentido, a importância de se observar e resguardar bacias de contribuição de nascentes e cursos d'água de unidades de conservação, pois pressões externas a montante podem impactar a qualidade dos sistemas hídricos no interior dos parques.

No Parque do Brejinho, o panorama geral mostra a variação de dados internos relativamente pequena. Entretanto, a comparação com os outros parques mostra um cenário geral de valores mais elevados, como no caso dos parâmetros STD, CE, alcalinidade, sódio e $\mathrm{pH}$. Esse fato pode derivar das condições de degradação e poluição local, agravadas pelas fortes pressões urbanas nas bacias de contribuição (poluição da superfície). O contexto brejoso e redutor da nascente BH10 é extremamente frágil, já que a água permanece retida por mais tempo e os poluentes tendem a se acumular (da mesma forma que a decomposição natural da matéria orgânica no ambiente). $\mathrm{O}$ Parque Vila Clóris também apresenta nascentes em contexto brejoso semelhante, estando abandonado e com abundância de lixo dentro de seus limites.

O presente trabalho aponta que as áreas úmidas comuns nos parques municipais de Belo Horizonte podem ter uma relevância hidroambiental subestimada e mesmo desconhecida, em termos geoquímicos, merecendo maior aprofundamento do seu estudo. O ambiente redutor e acidificado pode induzir reações geoquímicas de retenção ou liberação de íons, ao mesmo tempo em que pode modificar certos parâmetros, tais como o $\mathrm{pH}$, a alcalinidade e a Condutividade Elétrica. No contexto da malha metropolitana, com paisagens e sistemas hídricos bastantes 
artificializados, esse papel é, geralmente, desconsiderado. A gestão adequada do território urbano passa, portanto, pela proteção desses sistemas brejosos que, quando degradados ou abandonados, podem ser palco da proliferação de vetores de doenças e criação de ambientes insalubres. Nesses casos, a própria população pode ser levada a demandar a sua remoção dos espaços urbanos. Por outro lado, quando bem protegidas e conservadas, essas áreas úmidas urbanas podem contribuir para os atributos paisagísticos dos parques, atraindo a população para o melhor usufruto do espaço.

Os resultados mostram a importância da qualidade da água como indicadora das pressões antrópicas nos parques de Belo Horizonte, já que catalisam pressões e impactos existentes em toda a bacia de contribuição de cada ponto dos sistemas hídricos, inclusive nas áreas externas aos parques. Ainda que transmita um panorama parcial e que demande a complementação com dados ambientais de outras naturezas, o estado da água de nascentes e cursos d'água de baixa ordem podem contribuir com a gestão e a proteção dos parques municipais. Partindo-se do pressuposto de que as unidades de conservação são recortes territoriais mais protegidos, espera-se que os problemas de degradação ambiental não estejam presentes de modo sistemático. A manutenção do bom estado ambiental dos parques municipais e a atenção para a poluição superficial nas bacias de contribuição são as melhores estratégias para que sejam adequadamente apropriados e usufruídos pela sociedade.

\section{AGRADECIMENTOS}

Ao CNPq pela bolsa de pesquisa; ao Laboratório de Geomorfologia e Recursos Hídricos do IGC/UFMG; ao Grupo de Pesquisa RIVUS - Geomorfologia e Recursos Hídricos.

\section{REFERÊNCIAS}

ALMEIDA, D. C. B.; SANTOS, R. E. A. Doutrina Higienista e as canalizações de cursos d'água: o caso de Belo Horizonte. In: ENCONTRO NACIONAL DA ASSOCIAÇÃO NACIONAL DE PÓSGRADUAÇÃO E PESQUISA EM PLANEJAMENTO URBANO E REGIONAL - ENANPUR. 18., 2019. Natal. Anais... Natal. 2019. p. 25.

ALMEIDA M. R.; LAURA, S. C. R.; GLEICE, M. S. Análise microbiológica de água potável em parques do Município de Belo Horizonte/MG. Acta Biologica Brasiliensis, Belo Horizonte, v. 1, n. 1, p. 21-31, 2018.

APHA - AMERICAN PUBLIC HEALTH ASSOCIATION; AWWA - AMERICAN WATER WORKS ASSOCIATION; WEF - WATER ENVIRONMENT FEDERATION. Standard Methods for Examination of Water and Wastewater. CDR Edition. Washington: APHA, 2012. 1496p.

BRASIL. CONSELHO NACIONAL DE MEIO AMBIENTE. Resolução $\mathbf{n}^{\mathbf{0}} \mathbf{3 5 7}$, de 17 de março de 2005. Disponível em: <http://www2.mma.gov.br/port/conama/legiabre.cfm?codlegi=459>. Acesso em: 5 jul. 2020. 
BRITO, F. S. R. Função social do engenheiro sanitário (1909). Economia Sociologia e Moral, Rio de Janeiro, vol. XXII, 1943.

BOVO, M. C.; AMORIM, M. C. C. T. Análise e diagnóstico dos parques urbanos em Maringá (PR) Brasil. Geo UERJ, Rio de Janeiro, v. 2, n. 22, p. 323-349, 2011.

CBH RIO DAS VELHAS. Unidade Territorial Estratégica Ribeirão Onça. Disponível em: $<$ https://cbhvelhas.org.br/onca/>. Acesso em: 5 jul. 2020.

CPRM - SERVIÇO GEOLÓGICO DO BRASIL. Carta geológica de Belo Horizonte. Escala 1:100.000. $\quad$ CPRM, 2000. Disponível em: $<$ http://www.cprm.gov.br/publique/media/geologia_basica/pgb/mapa_bh.pdf $>$. Acesso em: 5 jul. 2020.

CRUZ, I. Por que Belo Horizonte submergiu nas chuvas de 2020. Nexo Jornal, 2020. Disponível em: $\quad<$ https://www.nexojornal.com.br/entrevista/2020/01/30/Por-que-Belo-Horizonte-submergiunas-chuvas-de-2020>. Acesso em: 30 jan. 2020.

DERÍSIO, J. C. Introdução ao controle de poluição ambiental. 5. ed. São Paulo: Oficina de Textos, 2016. 232p.

ESPÍNDOLA, E. L. G. A.; SILVA, J. S. V.; MARINELlI, C. E.; ABDON, M. M. Bacia Hidrográfica do Rio Monjolinho: uma abordagem ecossitêmica e a visão interdisciplinar. 1. ed. RiMa: São Carlos, 2000. 188p.

FELIPPE, M. F. Caracterização e Tipologia de Nascentes em Unidades de Conservação de Belo Horizonte-MG com Base em Variáveis Geomorfológicas, Hidrológicas e Ambientais. 2009. 277 f. Dissertação (Mestrado em Geografia e Análise Ambiental) - Instituto de Geociências, Universidade Federal de Minas Gerais, Belo Horizonte, 2009.

FELIPPE, M. F.; MAGALHÃES JR, A. P. A contribuição das nascentes na desnudação geoquímica: borda oeste da Serra do Espinhaço Meridional (Minas Gerais, Brasil). Revista Brasileira de Geomorfologia, São Paulo, v. 17, n. 1, p. 79-92, 2016.

FELIPPE, M. F.; MAGALHÃES JR, A. P. Impactos ambientais macroscópicos e qualidade das águas em nascentes de parques municipais em Belo Horizonte-MG. Revista Geografias, v. 8, n. 2, p. 08-23, 2012.

FELIPPE, M. F. ; MAGAlHÃES JR, A. P.; PESCIOTTI, H. A.; COELI, L. Nascentes antropogênicas: processos tecnogênicos e hidrogeomorfológicos. Revista Brasileira de Geomorfologia, São Paulo, v. 14, n. 4, p. 279-286, 2013.

FELIPPE, M. F. ; MAGALHÃES JR, A. P.; DEBIEN, B. R. Sistemas aquíferos de origem de nascentes em Lagoa Santa e Serra do Cipó (MG). Revista Brasileira de Geomorfologia, São Paulo, v. 16, n. 2, p. 283-300, 2015.

FERREIRA, L. L. B. Tipologia e Inventário de Áreas Úmidas Urbanas em Belo Horizonte (MG). 2019. 212 f. Dissertação (Mestrado em Geografia) - Instituto de Geociências, Universidade Federal de Minas Gerais, Belo Horizonte, 2019a. 
FERREIRA, L. L. B.; MAGALHÃES JR, A. P. Inventário das Áreas Úmidas urbanas em Parques Municipais de Belo Horizonte/MG. Caderno de Geografia, Belo Horizonte, v. 28, n. 54, p. 702$730,2018$.

FERREIRA, L. L. B.; GOMES, C. S.; MAGALHÃES JR, A. P. Contradições entre as ações públicas municipais de controle de inundações e as de proteção de sistemas hídricos em Belo Horizonte (MG): o caso do Parque Ecológico do Brejinho. REAPCBH - Revista Eletrônica do Arquivo Público da Cidade de Belo Horizonte, Belo Horizonte, v. 6, n. 6, p. 138-155, 2019 b.

FERREIRA, L. L. B.; MAGALHÃES JR, A. P.; FELIPPE, M. F.; COSTA, F. C. Considerações sobre perdas geoquímicas em nascentes e sistemas fluviais de cabeceiras de drenagem na borda oeste do Espinhaço Meridional (Minas Gerais). In: SIMPÓSIO BRASILEIRO DE GEOGRAFIA FÍSICA APLICADA. 17., 2017, Campinas. Anais... Campinas, 2017. p. 5991-6002.

FJP - FUNDAÇÃO JOÃO PINHEIRO. Saneamento básico em Belo Horizonte: trajetória em 100 anos - os serviços de água e esgoto. 1 ed. Belo Horizonte: Fundação João Pinheiro, 1997. 314p.

GOMES, P. M.; MELO, C.; VALE, V. S. Avaliação de impactos ambientais em nascentes na cidade de Uberlândia-MG: análise macroscópica. Revista Sociedade \& Natureza, Uberlândia, v. 32, n. 17, p. 103-120, 2005.

HOYUELA JAYO, J. A.; BORSAGLI, A.; MESQUITA, Y. Paisagem, Memória e Utopia durante o processo de construção da Nova Capital de Minas. In: Seminário Ibero-americano Arquitetura e Documentação, 4., 2015, Belo Horizonte. Anais... Belo Horizonte, 2015.

IBGE - INSTITUTO BRASILEIRO DE GEOGRAFIA E ESTATÍSTICA. Censo Demográfico de 2010. 2020. Disponível em: < http://cidades.ibge.gov.br/v4/brasil/mg/belo-horizonte/panorama $>$. Acesso em: 21/04/2020.

IBGE - INSTITUTO BRASILEIRO DE GEOGRAFIA E ESTATÍSTICA. Mapa de climas do Brasil. Brasília: IBGE, 2002. 1 mapa, color. Escala 1:5.000.000.

IBGE - INSTITUTO BRASILEIRO DE GEOGRAFIA E ESTATÍSTICA. Mapa de biomas do Brasil. Brasília: IBGE, 2004. 1 mapa, color. Escala 1:5.000.000.

IBGE - INSTITUTO BRASILEIRO DE GEOGRAFIA E ESTATÍSTICA. Mapa de solos do Brasil. Brasília: IBGE, 2001. 1 mapa, color. Escala 1:5.000.000.

IBGE - INSTITUTO BRASILEIRO DE GEOGRAFIA E ESTATÍSTICA. Mapa de vegetação do Brasil. Brasília: IBGE, 2004. 1 mapa, color. Escala 1:5.000.000.

INMET - INSTITUTO NACIONAL DE METEOROLOGIA. INMET 004/17: Estação Chuvosa em Minas Gerais. Belo Horizonte, INMET, 2017. Disponível em:<https://portal.inmet.gov.br/notasTecnicas $>$. Acesso em: 15/07/2020.

INMET - INSTITUTO NACIONAL DE METEOROLOGIA. BDMEP - Banco de Dados Meteorológicos para Ensino e Pesquisa. INMET, 2020. Disponível em: $<$ http://www.inmet.gov.br/portal/index.php?r=bdmep/bdmep $>$. Acesso em: 25/06/2020.

MAGALHÃES JR, A. P.; FERREIRA, L. L. B.; FELIPPE, M. F.; COSTA, F. C.; HORN, A. H. Relações entre perdas geoquímicas e configuração geomorfológica de bacias fluviais de baixa 
ordem na borda oeste do Espinhaço Meridional (Minas Gerais). Revista Brasileira de Geomorfologia, São Paulo, v. 19, n. 2, p. 303-319, 2018.

MARTINS, L. F. V.; VENTURI, L. A. B.; WINGTER, G. B. Proposta de um sistema para o monitoramento de parques urbanos em fundo de vale. Revista Ambiente e Sociedade, São Paulo, v. 22, 2019.

MINAS GERAIS - CONSELHO ESTADUAL DE MEIO AMBIENTE. Deliberação Normativa conjunta COPAM/CERH-MG $\mathbf{n}^{\mathbf{0}} \mathbf{1}$, de 05 de maio de 2008. Belo Horizonte, COPAM, 2008. Disponível em: <http://www.siam.mg.gov.br/sla/download.pdf?idNorma=8151\#: :text=10\%20E. Acesso em 25/06/2020.

PBH - PREFEITURA MUNICIPAL DE BELO HORIZONTE. Fundação de Parques Municipais e Zoobotânica. Belo Horizonte, atualizado em 09/03/2020. Disponível em: $<$ https://prefeitura.pbh.gov.br/fundacao-de-parques-e-zoobotanica $>$. Acesso em: 25 abr. 2020.

PBH - PREFEITURA MUNICIPAL DE BELO HORIZONTE. Parque Ecológico do Brejinho. Belo Horizonte, atualizado em 09/03/2020. Disponível em: $<$ https://prefeitura.pbh.gov.br/fundacaode-parques-e-zoobotanica/informacoes/parques/parque-ecologico-do-brejinho $>$. Acesso em: 25 abr. 2020.

PBH - PREFEITURA MUNICIPAL DE BELO HORIZONTE. Parque Municipal Lagoa do Nado. Belo Horizonte, atualizado em 09/03/2020. Disponível em: $<$ https://prefeitura.pbh.gov.br/fundacao-de-parques-e-zoobotanica/informacoes/parques/parquelagoa-do-nado $>$. Acesso em: 25 abr. 2020.

PBH - PREFEITURA MUNICIPAL DE BELO HORIZONTE. Parque Municipal Ursulina Andrade Mello. Belo Horizonte, atualizado em 13/11/2019. Disponível em: $<$ https://prefeitura.pbh.gov.br/fundacao-de-parques-e-zoobotanica/informacoes/parques/parqueursulina-de-andrade-mello>. Acesso em: 25 abr. 2020.

PBH - PREFEITURA MUNICIPAL DE BELO HORIZONTE. Parque Vila Clóris. Belo Horizonte, atualizado em 25/07/2018. Disponível em: $<$ https://prefeitura.pbh.gov.br/fundacao-deparques-e-zoobotanica/informacoes/parques/parque-vila-cloris $>$. Acesso em: 25 abr. 2020.

PROJETO MANUELZÃO - UFMG. Barragem atropela Parque do Brejinho. Belo Horizonte, 2014. Disponível em: <https://manuelzao.ufmg.br/barragem-atropela-parque-do-brejinho/>. Acesso em: 26 abr. 2020.

RAMOS, G. D. M.; GASPAR, A.; GUERRA, C. A.; CHAGAS, V. R. S. Qualidade da água utilizada em indústrias de alimentos localizadas no estado do Rio de Janeiro. Revista Universidade Rural - Série Ciências da Vida, Rio de Janeiro, v. 27, n. 1, p. 33-39, 2007.

ROCHA, I. L.; SALOMÃO, L. C.; IWATA, B. F.; SOUZA, J. A. R.; MOREIRA, D. A. Qualidade ambiental das nascentes do Rio Paraim, extremo sul do Piaú. Revista Ibero Americana de Ciências Ambientais, v. 10, n. 3, p. 385-399, 2019.

SALGADO, A. R.; COLIN, F.; NALINI JÚNIOR, H. A. O papel da denudação geoquímica no processo de erosão diferencial no Quadrilátero Ferrífero/MG. Revista Brasileira de Geomorfologia, Uberlândia, v. 5, n. 1, p. 55-69, 2004. 
SANTOS, L. M. O meio natural em Belo Horizonte: caracterização e análise de potencial para uso e ocupação preservacionista. 2001. 207 f. Dissertação (Mestrado em Geografia) - Instituto de Geociências, Universidade Federal de Minas Gerais, Belo Horizonte, 2001.

Silva, A. B.; CARVAlho, E. T.; FANTI-NEL, L. M.; VIANA, C. S.; ROMANO, A. W. Estudos geológicos, hidrogeológicos, geotécnicos e geoambientais integrados no município de Belo Horizonte: projeto estudos técnicos para o levantamento da carta geológica do município de Belo Horizonte; relatório final. Belo Horizonte: IGC-UFMG-FUNDEP-PBH, 1995. 426p.

STRAHLER, A. N. Hypsometric (area-altitude) analysis and erosional topography. Geological Society of America Bulletin, v. 63, p. 1117-1142, 1952.

TOCHETTO, D.; FERRAZ, C. O urbanismo de Saturnino de Brito e as ressonâncias provocadas. Revista de Pesquisa em Arquitetura e Urbanismo, n. 22, p. 84-101, 2016.

ZHU, B.; YU, J.; QIN, X.; RIOUAL, P.; XIONG, H. Climatic and geological factors contributing to the natural water chemistry in an arid environment from watersheds in northern Xinjiang, China. Geomorphology, v. 153, p. 102-114, 2012. 